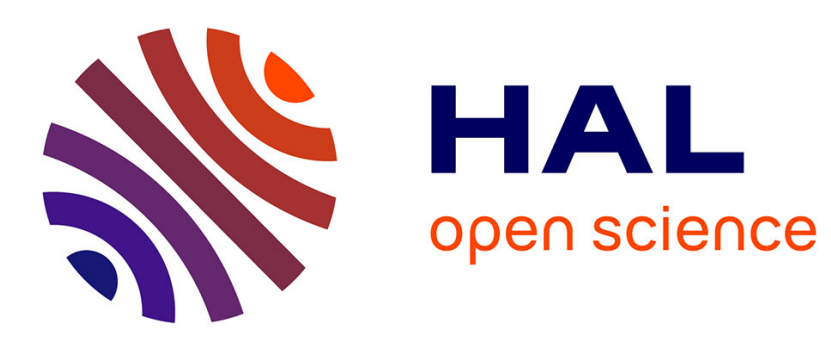

\title{
Fracture Energy Evaluation of Refractories in Wedge Splitting Tests from Notch Opening Displacements
}

\author{
R Vargas, R B Canto, François Hild
}

\section{To cite this version:}

R Vargas, R B Canto, François Hild. Fracture Energy Evaluation of Refractories in Wedge Splitting Tests from Notch Opening Displacements. Journal of the European Ceramic Society, 2021, 41 (10), pp.5367-5379. 10.1016/j.jeurceramsoc.2021.02.055 . hal-03154244

\author{
HAL Id: hal-03154244 \\ https://hal.science/hal-03154244
}

Submitted on 27 Feb 2021

HAL is a multi-disciplinary open access archive for the deposit and dissemination of scientific research documents, whether they are published or not. The documents may come from teaching and research institutions in France or abroad, or from public or private research centers.
L'archive ouverte pluridisciplinaire $\mathbf{H A L}$, est destinée au dépôt et à la diffusion de documents scientifiques de niveau recherche, publiés ou non, émanant des établissements d'enseignement et de recherche français ou étrangers, des laboratoires publics ou privés. 


\title{
Fracture Energy Evaluation of Refractories in Wedge Splitting Tests from Notch Opening Displacements
}

\author{
R. Vargas ${ }^{a, c}$, R.B. Canto ${ }^{a, b}$ and F. Hild ${ }^{c}$ \\ ${ }^{a}$ Federal University of São Carlos, Graduate Program in Materials Science and Engineering (PPGCEM), 13565-905, São Carlos-SP, Brazil \\ ${ }^{b}$ Federal University of São Carlos (UFSCar), Department of Materials Engineering (DEMa), 13565-905, São Carlos-SP, Brazil, Brazil \\ ${ }^{c}$ Université Paris-Saclay, ENS Paris-Saclay, CNRS, LMT - Laboratoire de Mécanique et Technologie, 91190 Gif-sur-Yvette, France
}

\section{ARTICLE INFO}

\section{Keywords:}

Crack mouth opening displacement (CMOD)

Digital Image correlation (DIC)

Refractory castable

Wedge Splitting Test (WST)

Work of Fracture

\begin{abstract}
A B S TR ACT
The work of fracture of refractories is commonly calculated from Crack Mouth Opening Displacements (CMODs) in Wedge Splitting Tests (WSTs). This paper proposes a methodology for estimating the fracture energy from Notch Opening Displacement (NOD) measurements, which is useful for setups where CMOD is not accessible. NODs and CMODs are calculated for both faces of two WSTs experiments on a castable refractory via Digital Image Correlation (DIC) and finite element simulations. A quadratic function fits well the non-linear CMOD vs. NOD behavior in the crack initiation regime, while an affine trend describes the propagation regime. Although the nonlinearity associated with crack initiation is more complex, the crack propagation energy can easily be estimated from NOD data when CMODs cannot be measured.
\end{abstract}

\section{Introduction}

The Wedge Splitting Test (WST) is an experiment that uses one wedge to convert the applied axial force into intensified splitting forces [1,2]. This configuration leads to a smaller elastic energy stored in the testing frame, thereby allowing for stable crack propagation in brittle materials since when fracture initiates there is no sudden release of stored energy [3]. Some common experiments (e.g., uniaxial tensile tests) are not suitable for these materials since the brittleness may lead to fracture in the grips apart from sudden failure after one crack has initiated. The usual geometry considered in WSTs also gives a high fracture surface to specimen volume ratio [4], which helps obtaining trustworthy results even with small specimens. One additional advantage is that no special shape is needed, the only requirement being that notches can be made in the structure to be tested [5]. In the following analyses, standard shapes were considered with the loading system proposed in Ref. [6].

The main output from WSTs is the fracture energy [5]. The total work performed during the test is calculated by integrating the force applied by the testing machine and the actuator displacement. However, this measure accounts for the elastic energy stored in the testing frame and frictional components, and thus overestimates the work of fracture [5, 7]. "Deformations for the determination of fracture energy must always be measured by means of transducers, strain gauges, etc., fixed on the specimen." [5]. One important piece of information then becomes the Crack Mouth Opening Displacement (CMOD), which is the dual variable associated with the splitting force.

CMODs are usually measured with extensometers or clip gauges [5]. However, optical methods can also be used [8]. Among them, Digital Image Correlation (DIC) [9] has been utilized in WSTs to measure CMODs [7, 10-12] by considering two interrogation windows on either side of the top part of the sample (Figure 1(a)). Notch Opening Displacements (NODs) were also assessed via DIC [13-15]. Displacement fields [7, 10, 16-20] or strain fields [1113, 21-39] were mostly measured to assess the crack path, crack branching and crack length. Another advantage of such measurement technique is that it can also be deployed when performing high temperature WSTs [12, 40]. In one such application, an additional issue arose because standard furnaces may not allow front and/or back sample surfaces to be fully monitored by digital cameras [41]. Figure 1(b) illustrates that situation for which it was decided to focus image acquisitions along the propagation path. Under such conditions, the areas required for CMOD measurements were no longer visible. The dark areas in the corners of Figure 1(b) are related to obscuration of the illumination

\footnotetext{
*Corresponding author

@email@institution (R. Vargas)

ORCID(s): 0000-0002-1711-9804 (R. Vargas); 0000-0002-9286-9912 (R.B. Canto); 0000-0001-5553-0066 (F. Hild)
} 
setup of the furnace. The test related to Figure 1(b) was performed at room temperature (but inside the furnace) to prepare the following high-temperature tests [41] that are not discussed herein. The question to be addressed in the following analyses is how the NOD can be extrapolated to evaluate CMOD even though it may not be measurable in some instances.

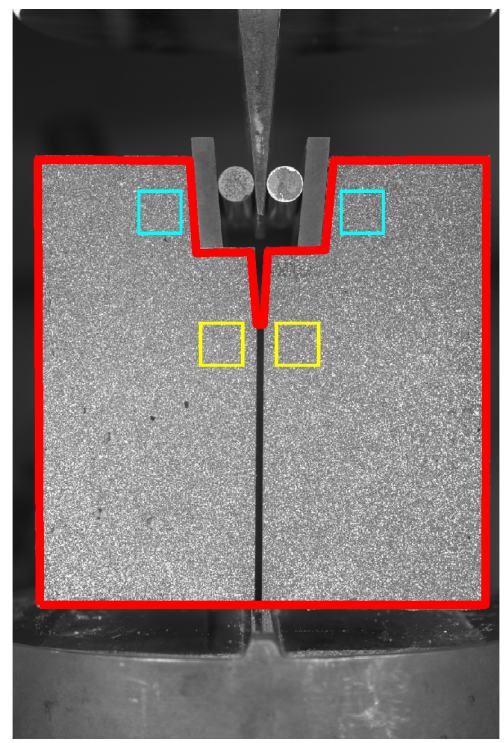

(a)

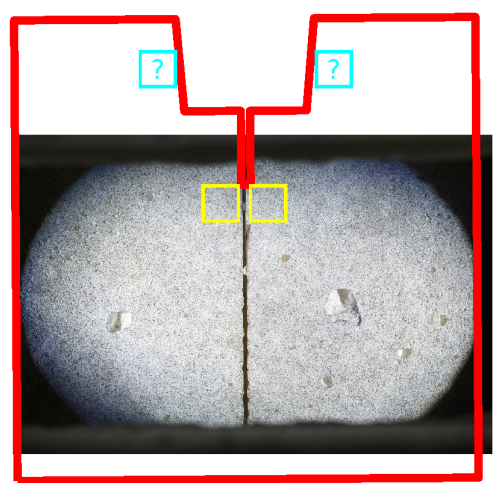

(b)

Figure 1: Images of front faces of WSTs: (a) monitoring the whole surface (CMOD and NOD were accessible) and (b) photographed through a quartz window (e.g., inside a furnace) with limited field of view (i.e., with no access to CMOD). The cyan boxes are regions of interest for DIC analyses to evaluate CMODs, and the yellow boxes depict the areas used for NOD measurements

The outline of the paper is as follows. First, the CMOD vs. NOD histories are analyzed for two different WST experiments on the same anti-erosive refractory castable, one monotonic with full crack propagation and no grooves on front/back faces, and another (cyclic) one on a grooved sample with the test stopped after reaching the ultimate load and until the load decreases by $30 \%$ due to crack propagation. These two cases correspond to the configuration shown in Figure 1(a). Then, the CMOD vs. NOD relationship is numerically investigated for brittle propagation and also using cohesive elements, before the fracture energies are (experimentally and numerically) estimated. Last, another experimental case for an alumina-mullite-zirconia refractory where the CMOD region was not visible (Figure 1(b)) is studied as an example of applying the methodology developed herein.

\section{Experimental NOD vs. CMOD Histories on DD40 Grade}

In the following, NOD vs. CMOD histories are extracted from DIC analyses of two WSTs on an anti-erosive commercial refractory castable (grade DD40 [42-44]). This composition is one candidate to be applied in fluidized catalytic cracking units in petrochemical industries. Coke impregnation may alter its microstructure [42] and affect its fracture energy [43]. If applied close to $570{ }^{\circ} \mathrm{C}$, temperature fluctuations can lead to quartz phase transformation and considerably damage the material [44]. This material contains quartz, mullite, kyanite, $\beta$-cristoballite and alumina. The oxide composition consists of $50 \mathrm{wt} \% \mathrm{SiO}_{2}, 45 \mathrm{wt} \% \mathrm{Al}_{2} \mathrm{O}_{3}$ and small fractions of $\mathrm{Fe}_{2} \mathrm{O}_{3}$ and $\mathrm{CaO}$ [16]. The DD40 samples analyzed herein were fired at $540{ }^{\circ} \mathrm{C}$. In both experiments, the whole front and back faces were monitored. The front face of the grooved sample corresponds to the case shown in Figure 1(a), with its actual geometry displayed in Figure 2. 


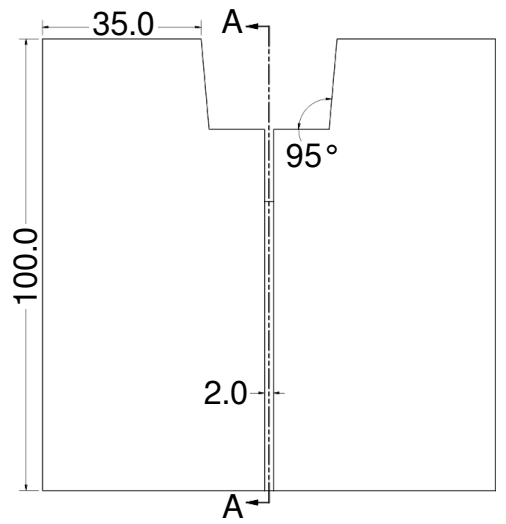

(a)

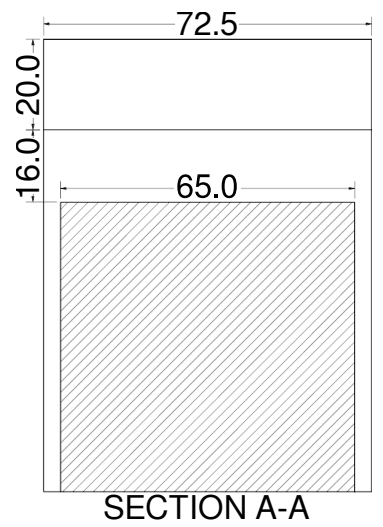

(b)

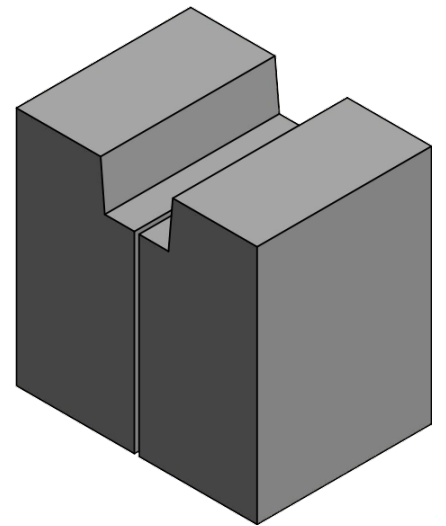

(c)

Figure 2: Grooved sample geometry (dimension expressed in $\mathrm{mm}$ ). (a) Frontal view. (b) Lateral A-A section. (c) Isometric view.

\subsection{Monotonic Test}

First, a monotonic WST is studied (Figure 3). Similar tests were used to check the effect of coke impregnation on the fracture energy of DD40 since this composition can be used in petrochemical industries [43]. In the present case, no groove was implemented and crack branching was observed [45] and quantified [46] on the monitored surfaces. The CMODs and NODs can then be measured with two sets of optical gauges per analyzed surface (Figures 3(b-c)).

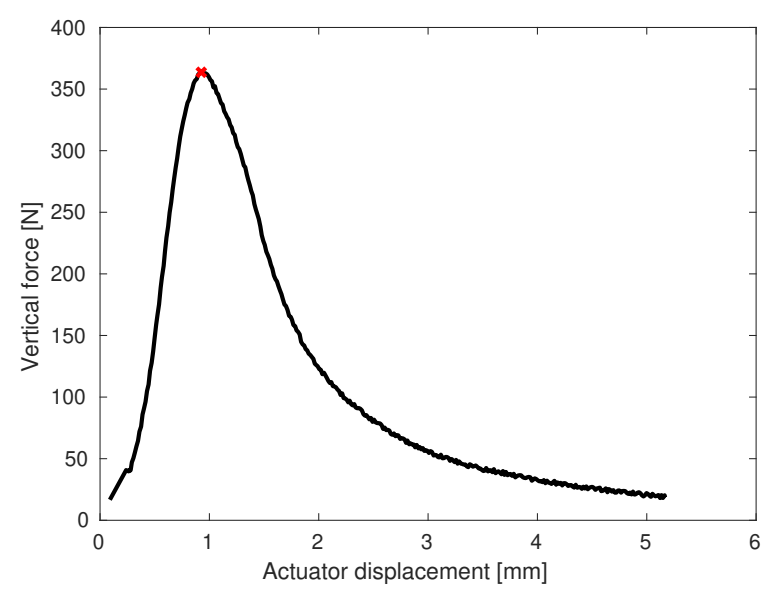

(a)

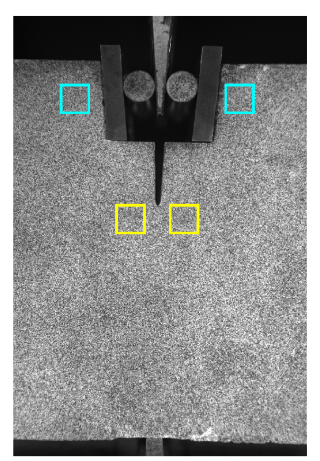

(b)

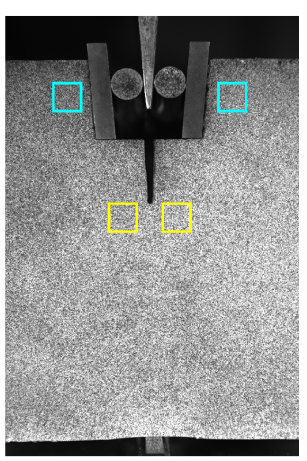

(c)

Figure 3: (a) Load history of the monotonic WST carried out on DD40 grade. The red cross depicts the ultimate force level. Reference images with the optical gauges for CMOD (cyan) and NOD (yellow) measurements for the (a) front and (b) back faces

To evaluate the measurement uncertainties, 12 pictures of the reference configuration were available. DIC analyses were then run on this series of pictures for the optical gauges shown in Figures 3(b-c). For each of them, the mean displacement was computed, then the NOD and CMOD. Their temporal variances were assessed, and the root mean level of these two variances is referred to as standard NOD/CMOD uncertainty $\sigma_{u}$. In the present case, $\sigma_{u}$ was found to be equal to $0.5 \mathrm{cpx}$ (or $0.24 \mu \mathrm{m}$ ) in the horizontal direction for both faces.

The CMOD $\Delta$ vs. NOD $\delta$ plots are shown in Figure 4 for both analyzed surfaces. Their magnitude is significantly larger than the measurement uncertainties. Thus these results are deemed trustworthy. Two regimes are observed. First, a nonlinear relationship arises between these two quantities up to the ultimate load (red crosses that depict the 


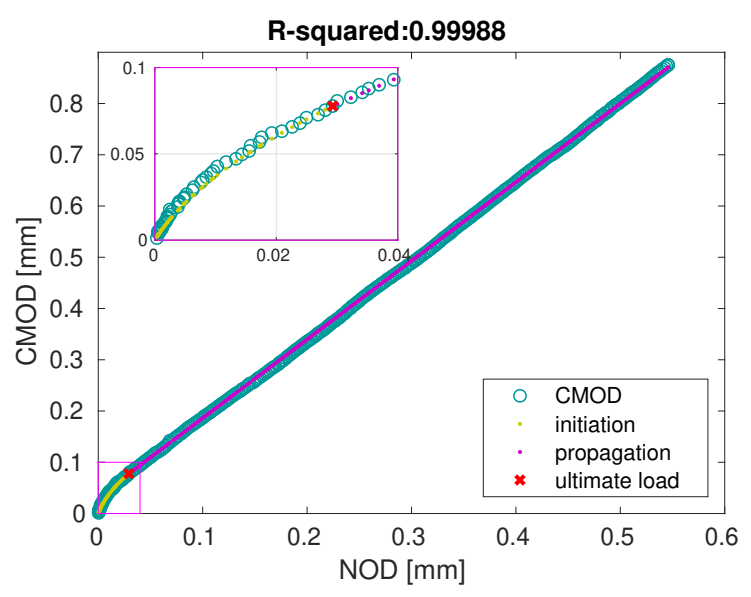

(a)

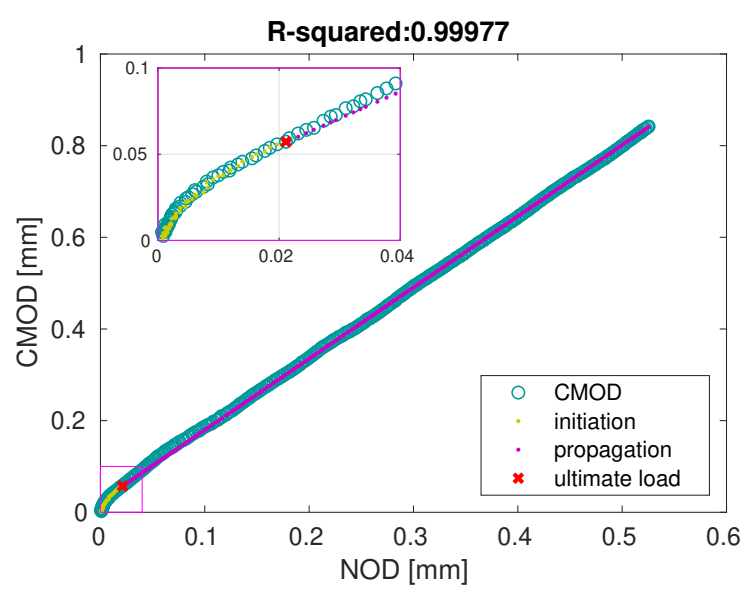

(b)

Figure 4: CMOD vs. NOD histories in the monotonic test on DD40 for the front (a) and back faces (b). The quadratic and affine fits are also shown in yellow and purple, respectively. The insets (purple boxes) concentrate on low levels of NOD and CMOD up to the ultimate load (red cross)

NOD and CMOD at the ultimate load, see Figure 3(a)), which presumably corresponds to the initiation step of the main macrocrack [47-53]. This hypothesis will be further discussed in the sequel. A quadratic interpolation

$$
\bar{\delta}=a \bar{\Delta}^{2}+b \bar{\Delta} \quad \text { with } \quad \bar{\delta}=\frac{\delta}{\delta\left(F_{\max }\right)} \quad \text { and } \quad \bar{\Delta}=\frac{\Delta}{\Delta\left(F_{\max }\right)}
$$

is observed to be a good approximation, where $a$ and $b$ are parameters to be calibrated. Conversely, an affine trend is found to be satisfied in the post-peak regime (i.e., beyond the ultimate load)

$$
\bar{\delta}-1=\frac{\Delta\left(F_{\max }\right)}{c \delta\left(F_{\max }\right)}(\bar{\Delta}-1)
$$

where $c$ is the slope of the $\Delta$ vs. $\delta$ interpolation. The two portions are made $\mathrm{C}^{1}$ continuous at the peak load $\left(F=F_{\max }\right)$. Consequently, only one independent parameter is to be considered, namely, $c \delta\left(F_{\max }\right) / \Delta\left(F_{\max }\right)$ in the dimensionless plot $\bar{\Delta}$ vs. $\bar{\delta}$ since

$$
a=\frac{\Delta\left(F_{\max }\right)}{c \delta\left(F_{\max }\right)}-1 \quad \text { and } \quad b=1-a
$$

Conversely, in the original frame, namely, $\Delta$ vs. $\delta$, three parameters are needed: $\Delta\left(F_{\max }\right), \delta\left(F_{\max }\right)$ and $c$.

In the present case, $c \delta\left(F_{\max }\right) / \Delta\left(F_{\max }\right)=1.73$ and 1.74 with a very good agreement with the experimental measurements (i.e., the coefficient of determination, or Pearson's $R^{2}$, is very close to one, see Figure 4 ); the corresponding ratio $\delta\left(F_{\max }\right) / \Delta\left(F_{\max }\right)=2.33$ and 2.27. Moreover, the root mean square error of the fit and the experimental data normalized by the standard uncertainty (i.e., $\chi_{\Delta}$ ) is about 14 , which is deemed very small considering this simple description. Such observations apply to both faces. This result indicates that a very simple relationship may be envisioned to relate CMOD to NOD, especially after the maximum sustained load (i.e., affine interpolation). Further, the slope $c$ for the analyses of the front and back faces are very close (i.e., $1.54 \pm 0.01$ ) and their difference may be due to the fact that the crack did not propagate along a straight path.

\subsection{Cyclic Test}

The second case deals with a cyclic test. Global fracture parameters [16] and those of a cohesive zone model [10] were calibrated with the use of DIC analyses. The cyclic force vs. displacement curve is shown in Figure 5(a). It is worth noting that this test was only performed until $70 \%$ of ultimate load in the post-peak regime (green circle in Figure 5(a)), which does not give complete insight into the propagation regime in comparison to the previous test 
(Figure 3). Figure 5(b-c) present the regions where the NOD and CMOD were measured on both surfaces. In the present case, grooves were present and the crack propagated along this predetermined path [7].

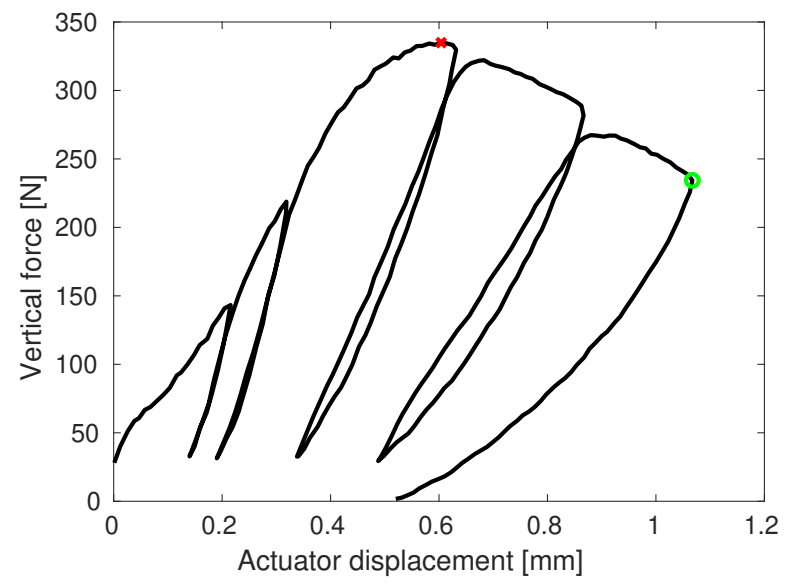

(a)

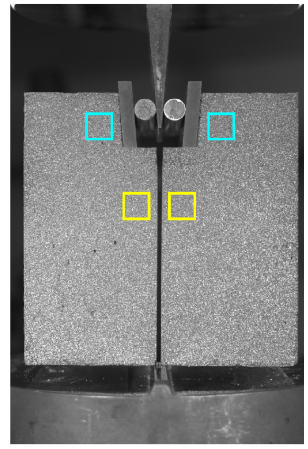

(b)

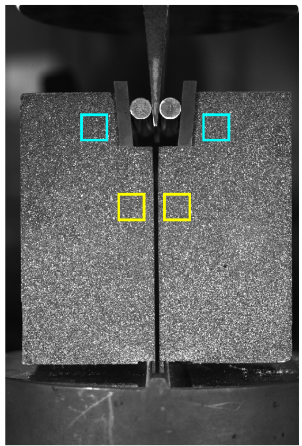

(c)

Figure 5: (a) Load history of the cyclic WST carried out on DD40 grade. The red cross depicts the ultimate force level and the green circle $70 \%$ of the ultimate load (i.e., the end of the envelope). Reference images with the optical gauges for CMOD (cyan) and NOD (yellow) measurements for the front (a) and back (b) surfaces

Since only one reference image was available for the uncertainty quantification, and the images were acquired in similar conditions, the same uncertainty $\sigma_{u}$ was considered for this case. With such hypothesis, the CMOD vs. NOD curves reported in Figure 6 are also deemed trustworthy. First, only the loading envelope was considered, which was useful for the extraction of the fracture energy [7]. The identified parameter $c \delta\left(F_{\max }\right) / \Delta\left(F_{\max }\right)=1.43 \pm 0.02$, and the curves are shown in Figure 6. The ratio at the ultimate load $\delta\left(F_{\max }\right) / \Delta\left(F_{\max }\right)=2.68 \pm 0.03$, slightly higher than in the monotonic case (with no groove). It is observed that the affine (for the post-ultimate load regime) and quadratic (pre-ultimate load) relationships (see Equations (1) and (2)) are also suitable (i.e., the coefficient of determination still is close to one and $\chi_{\Delta}=8$ ). The slopes of the analyses of front and back faces are close (i.e., $\left.c=1.61 \pm 0.04\right)$. When compared to the previous case, the nonlinear trend prior to the peak load is identical (see insets of Figure 4).

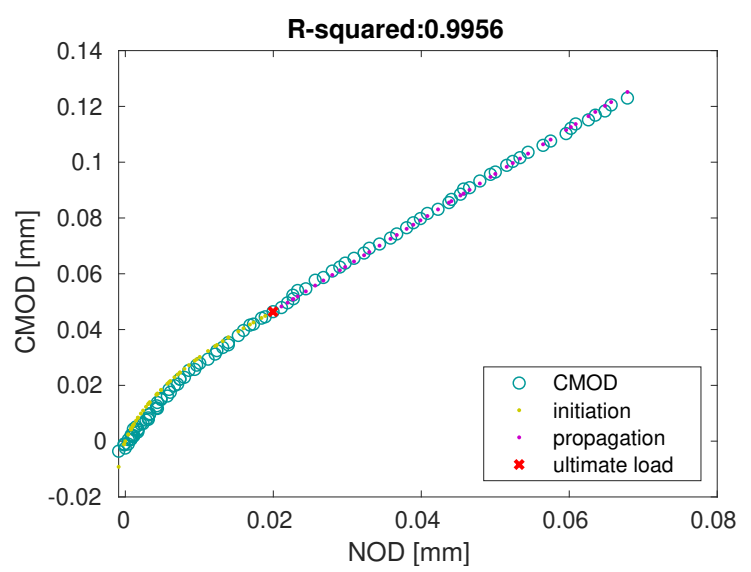

(a)

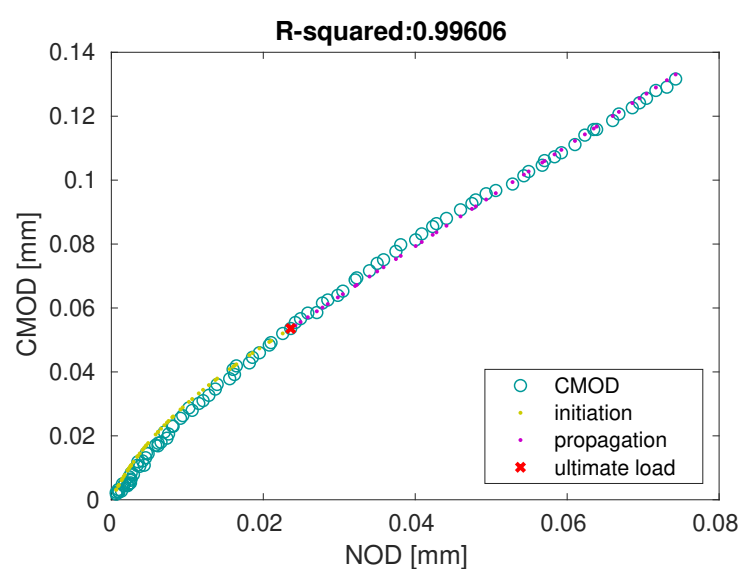

(b)

Figure 6: CMOD vs. NOD curves for the envelope response of the cyclic test for the (a) front and (b) back faces. The proposed description of crack initiation and the post-peak affine fits are shown in yellow and purple, respectively

For the sake of completeness, the full CMOD vs. NOD history is reported in Figure 7. It is interesting to note that the 
unloading/reloading parts are essentially affine (with varying slopes and virtually no hysteresis). Contrary to the early loading history, no non-linearity is observed. This remark applies to both sets of data. All these observations further point toward crack initiation as the likely cause of the initial nonlinear response. This point is further investigated in the following sections where the linear interpolation (blue curves) in Figure 7 are also explained.

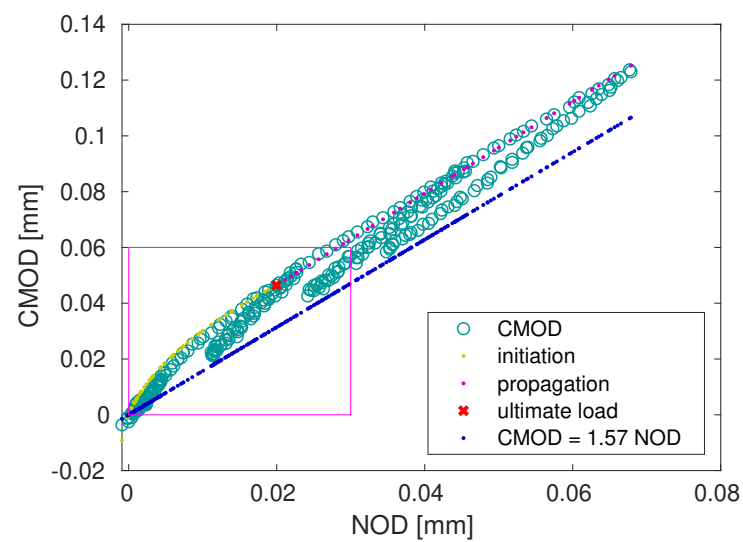

(a)

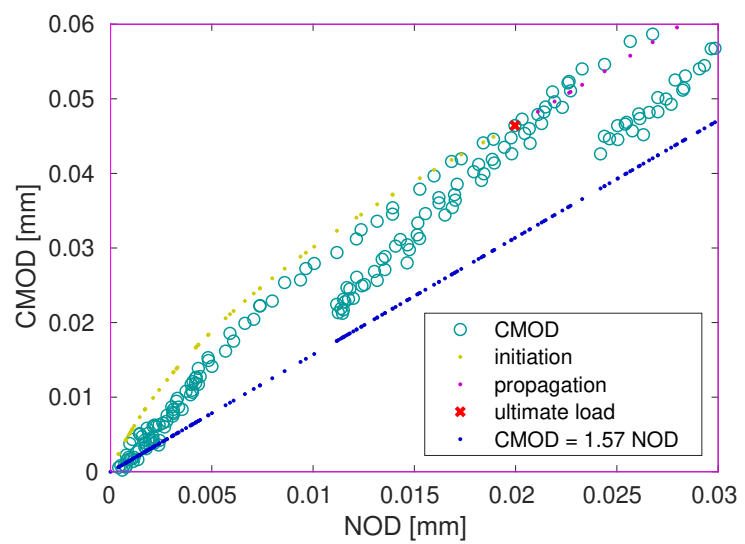

(c)

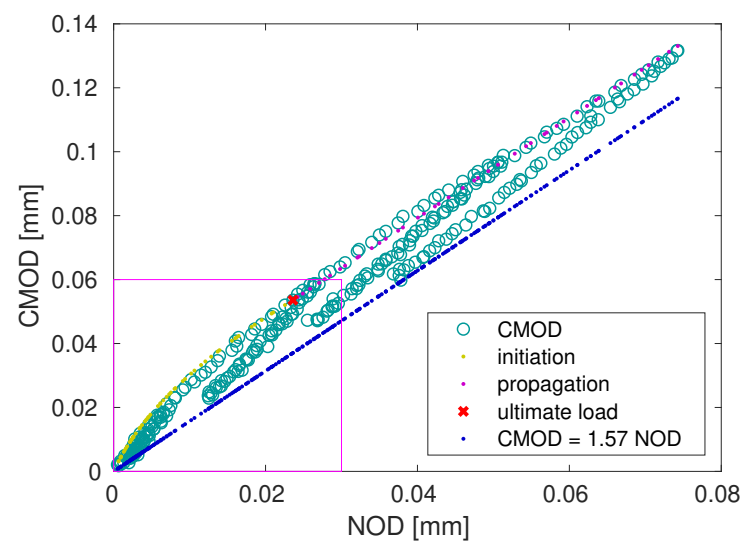

(b)

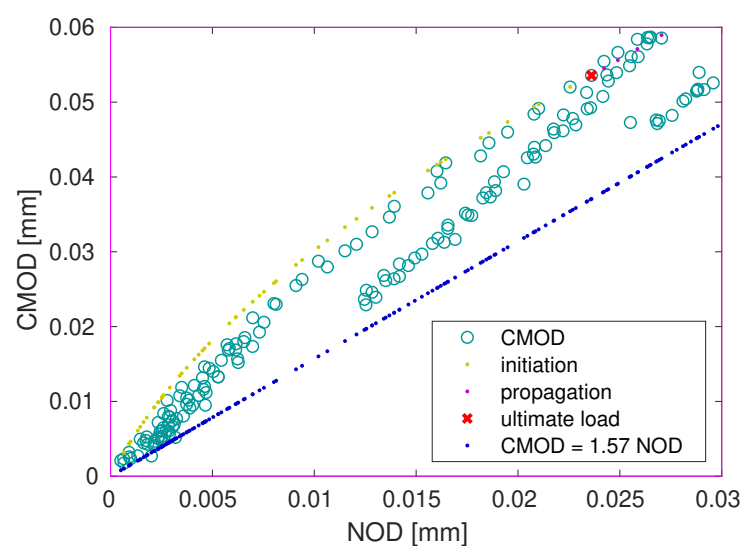

(d)

Figure 7: CMOD vs. NOD curves for the cyclic test for the (a) front and (b) back faces. The beginning of the test (magenta boxes) is shown in sub-figures (c) for the front and (d) back faces. The quadratic and affine fits are also shown in yellow and purple, respectively. The linear interpolation (blue dots) corresponds to Equation (4)

\subsection{NOD vs. CMOD Relationships}

As discussed above, CMOD data are needed for reliable fracture energy calculations. However, in some cases it may not be measurable (Figure 1(b)). In this first set of analyses, it was shown that a linear interpolation fits very well the CMOD vs. NOD relationship for post-peak crack propagation, and a parabolic interpolation for the pre-peak regime. For the cyclic case, the unloading parts led to more complex trends. One key parameter in the proposed interpolation is the ratio $\Delta\left(F_{\max }\right) / \delta\left(F_{\max }\right)$. In the two analyzed experiments, it was found that $\Delta\left(F_{\max }\right) / \delta\left(F_{\max }\right)=2.5 \pm 0.2$.

It is worth noting that an affine relationship was already proposed for fiber-reinforced concrete with WSTs on bigger samples [54]. In that case, NODs were sought when measuring CMODs. The authors used a unique affine fit based on FE simulations of the whole history. Such type of analysis is now carried out to further validate the proposed interpolation. 


\section{Numerical Analyses}

The aim of the following studies is to analyze CMOD vs. NOD relationships thanks to numerical simulations. In particular, the origin of the early non-linearity is investigated by comparing simulations with purely brittle propagation and with a cohesive zone model calibrated on the previous experiments. Apart from the cohesive zone (Section 3.2), a linear elastic behavior was assumed for the material whose Young's modulus was equal to $17 \mathrm{GPa}$ and Poisson's ratio was 0.2 .

\subsection{Brittle Propagation}

The first case is a virtual propagation experiment computed with the commercial finite element code Abaqus. The geometry is shown in Figure 8, where horizontal pressure was applied on the nodes depicted by blue circles. Vertical displacements were blocked for the two nodes with red circles. The vertical middle line of nodes were detached one by one to have a total of 184 propagation steps, with the remaining ligament in the propagation region of the final step being about $4 \mathrm{~mm}$. A plane strain assumption was made with CPE4 elements in the groove region and CPE3 elements elsewhere.

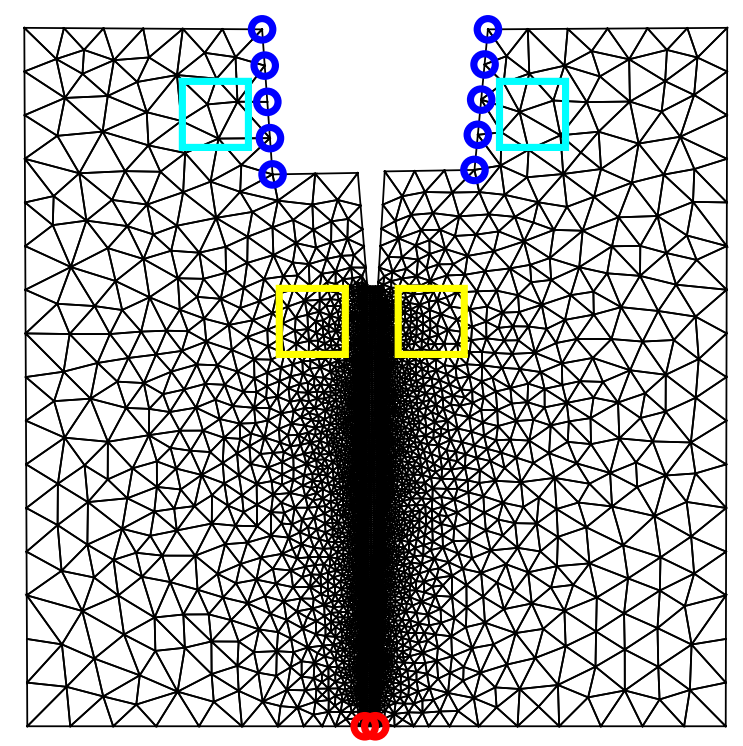

Figure 8: Finite element mesh (Figure 10(c)) for the simulation of brittle propagation. The blue nodes undergo the effect of uniform pressure, while the two bottom red nodes have no vertical motion. Nodes in the middle vertical plane are gradually detached to simulate different propagation steps. The cyan and yellow boxes mimic optical gauges for NOD and CMOD evaluations

For each propagation step, the NODs and CMODs were calculated from the mean displacements of the yellow and cyan gauges, respectively. Two cases were considered, namely, one with constant thickness (similar to the monotonic case of Section 2.1) and another one in which the presence of the groove was accounted for by varying the out-of-plane section in the grooved region (as in the cyclic case of Section 2.2). Figure 9 shows that a linear fit describes very well the NOD vs. CMOD relationship (i.e., a very close to unity R-squared correlation). The coefficients of proportionality are virtually identical for both investigated cases (their difference is less than $0.04 \%$ ). In the present simulations, no initiation was accounted for. This observation confirms that the non-linearity observed in both experimental cases was due to crack initiation. 


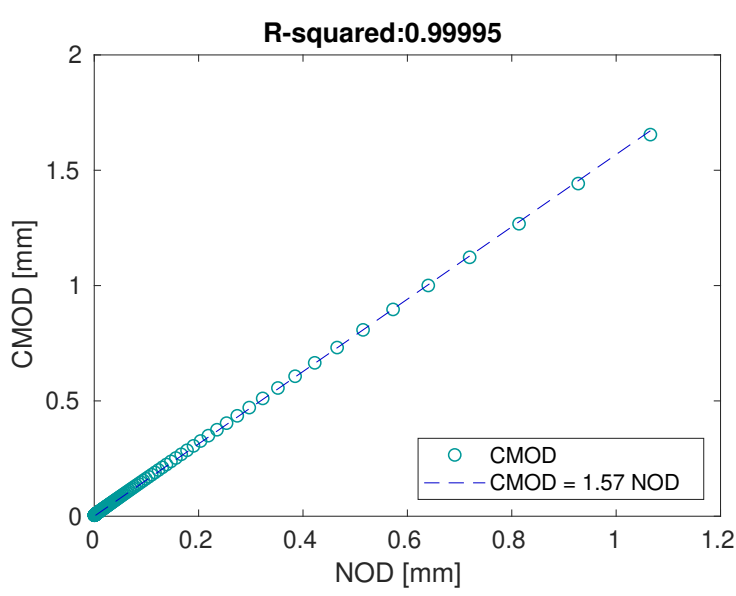

(a)

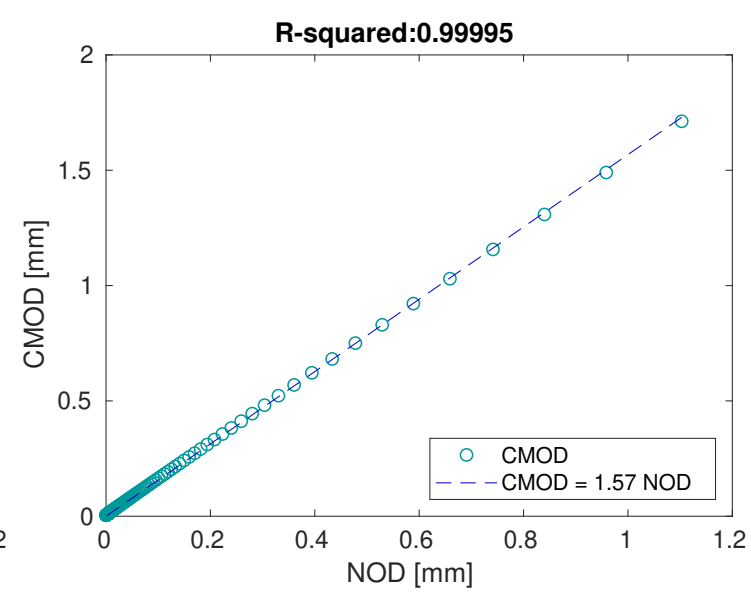

(b)

Figure 9: CMOD vs. NOD curves for the finite element case with (a) the same thickness in the whole sample and (b) reduced thickness in the grooved region. The linear fit is depicted with blue dashed lines

Consequently, a very simple relationship is obtained

$$
\Delta_{B P}=1.57 \delta
$$

that was used for the linear fit (blue dots) shown in Figure 7. It is observed that such interpolation corresponds to a lower bound (even for unloading/reloading paths), which is explained by the absence of crack initiation in this brittle propagation simulation. Conversely, the affine interpolation beyond the peak load provides an upper bound.

It is worth noting that the 1.57 factor depends on the NOD and CMOD gauge positioning. From a preliminary study [41], the proportionality coefficient was higher (i.e., 1.62) since the NOD gauge was not positioned at the same location as herein. Conversely, this factor is independent of the Young's modulus $E$ since any displacement is proportional to $E$.

\subsection{Initiation and Propagation Regimes}

In the following analyses, the so-called PPR model was selected $[55,56]$ to model crack initiation and propagation. For the cyclic test reported herein, a Finite Element Model Updating procedure was considered for the load envelope in which the global equilibrium gap $\chi_{F}$ (i.e., force residuals) was minimized via FEMU-F [10]. The same procedure was also followed to evaluate the cohesive strength $\sigma_{\max }$ and fracture energy $\boldsymbol{J}_{c}$ for the monotonic test. The initial stiffness parameter $(\lambda=0.005)$ and the shape parameter $(\alpha=7)$ were identical to those used in Ref. [10] for the cyclic test. The meshes constructed for identification purposes are shown in Figure 10. They are identical to that shown in Figure 8 (scaled and repositioned in the image frame as shown in Figure 10) but with cohesive elements in the middle vertical plane. 


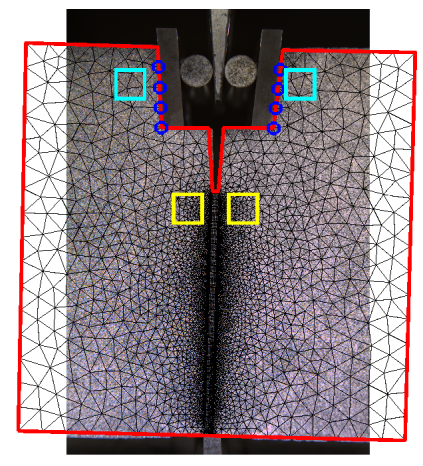

(a)

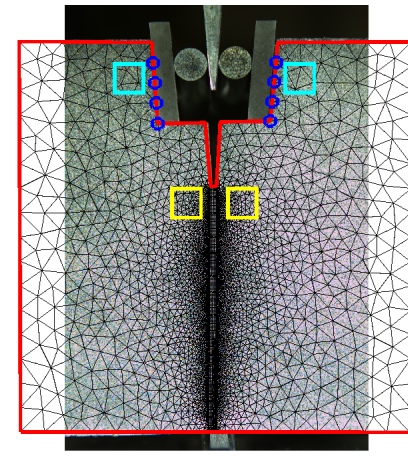

(b)

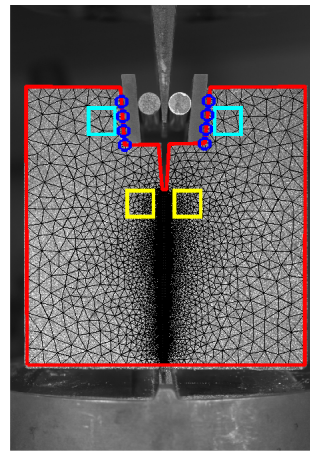

(c)

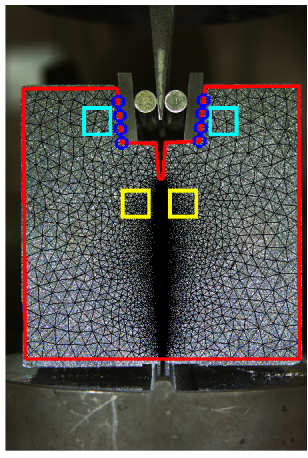

(d)

Figure 10: Meshes used for FEMU-F analyses for the calibration of the PPR model. (a-b) Monotonic WST. (cd) Cyclic [10]. The blue circles depict nodes where boundary conditions were applied [10]. Cyan and yellow boxes show the regions where CMOD and NOD were calculated

The calibrated parameters are reported in Table 1. It took 5 iterations to converge, mostly correcting for the boundary condition that is needed in the present cases [10]. When the identification procedure was started with the parameters calibrated for the cyclic test, which did not exhibit full crack propagation, but with the proper boundary condition correction, it converged in one single iteration for both faces of the monotonic case. This result is due to the fact that the cohesive parameters are very close for both experiments (i.e., the average cohesive strength is identical in both experiments, and there is a $7 \mathrm{~J} / \mathrm{m}^{2}$ difference for the mean fracture energy).

\section{Table 1}

Fracture energies and cohesive strengths for the two analyzed WSTs on DD40 grade. Results for the cyclic case after Ref. [10]

\begin{tabular}{|l|c|c|c|}
\hline Test & $J_{c}\left(\mathrm{~J} / \mathrm{mm}^{2}\right)$ & $\sigma_{\max }(\mathrm{MPa})$ & $\chi_{F}(-)$ \\
\hline \hline Monotonic (face 1) & 117 & 1.76 & 2.9 \\
Monotonic (face 2) & 112 & 1.67 & 3.7 \\
\hline Cyclic (face 1) & 100 & 1.84 & 2.0 \\
Cyclic (face 2) & 115 & 1.59 & 2.7 \\
\hline
\end{tabular}

The identification quality is assessed with the minimized quantity (i.e., $\chi_{F}$, which is the RMS force residual divided by the standard uncertainty of the load cell) and reported in Table 1 . The level of $\chi_{F}$ is less than four times the load uncertainty in all cases. This result shows that the selected CZM is able to describe accurately the two studied experiments, as additionally proven by the very close experimental and simulated CMOD vs. force responses shown in Figure 11. The small increase of $\chi_{F}$ in the monotonic test is due to the fact that the CZM was probed on a larger part of the experiment (i.e., it was stopped for a post-peak force of 5\% the ultimate load) in comparison to the cyclic test (70\% the ultimate load) and from deviations to the straight crack hypothesis [46, 57]. 


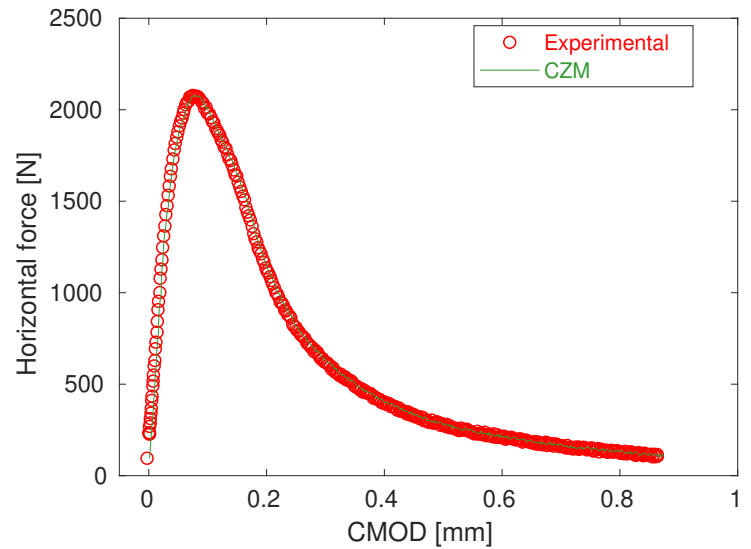

(a)

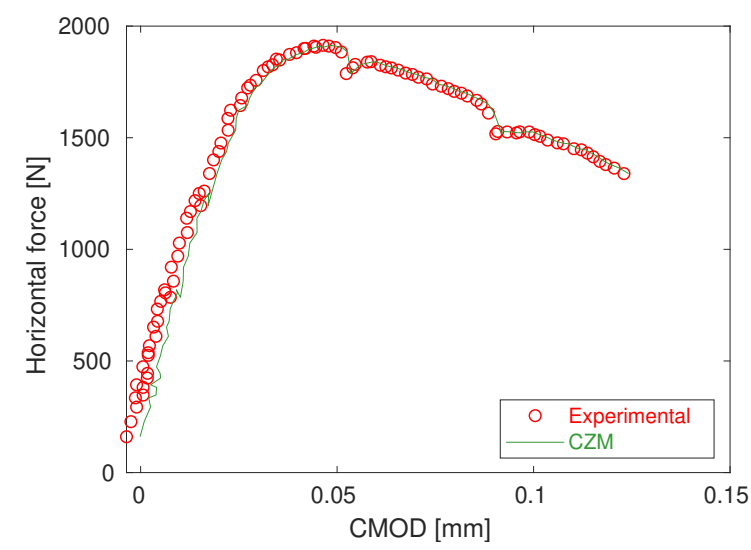

(c)

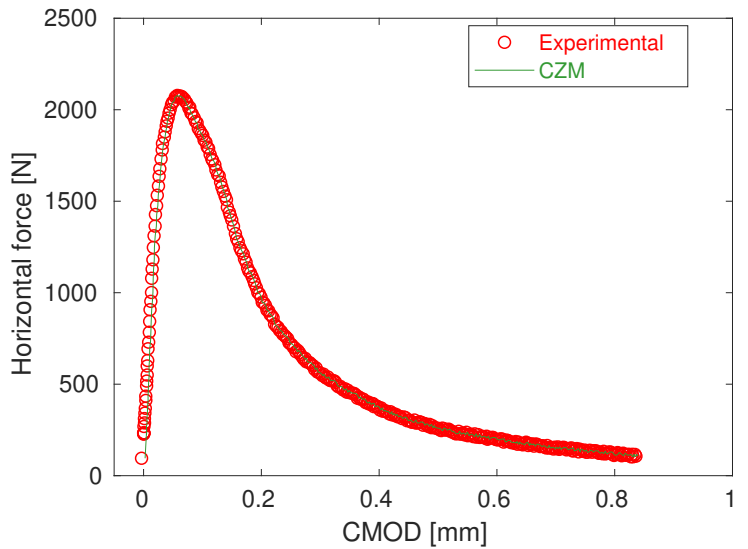

(b)

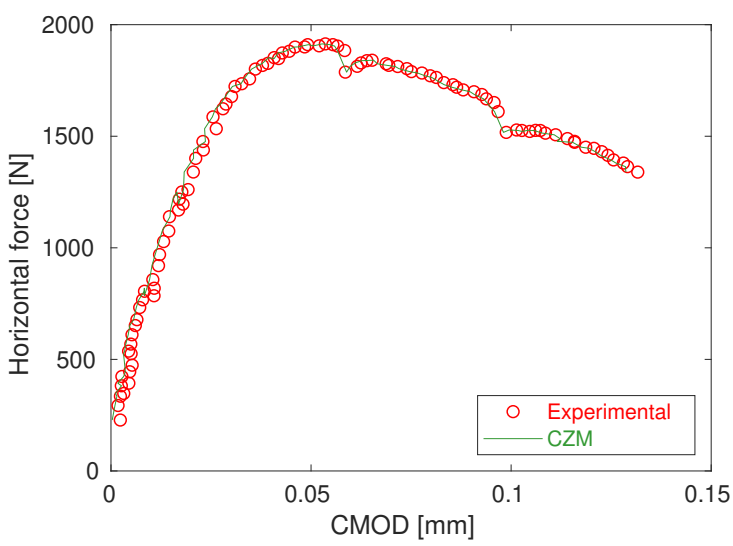

(d)

Figure 11: Horizontal force vs. CMOD of the monotonic (a-b) and cyclic (envelope) (c-d) experiments for the front $(a, c)$ and back $(b, d)$ faces. The experimental results are shown in red while the results for the converged calibration of the CZM in green

Once the CZM parameters were calibrated, the NOD and CMOD histories were assessed by following the same way as in the experimental analyses, starting off with the monotonic case (Figure 12). In terms of overall trends, the results are fully consistent with the experimental observations (Figure 4). In particular, a very high coefficient of determination is also observed for the proposed interpolation and $\chi_{\Delta}=13$, which are very close to the level of agreement observed experimentally. The only small difference is related to the slope, which is equal to 1.50 in both simulations in comparison to $1.54 \pm 0.01$ for the experimental levels. The early nonlinear response is also captured with the CZM and the corresponding quadratic fit (see insets of Figures 4 and 12). 


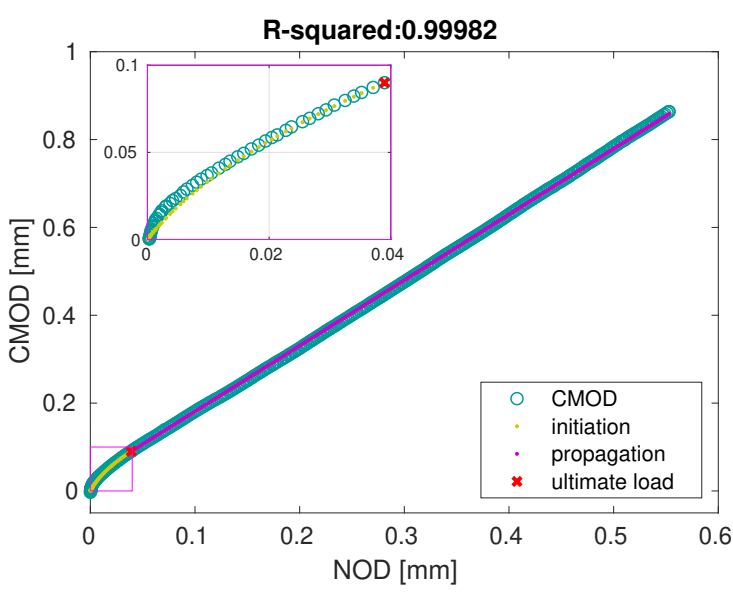

(a)

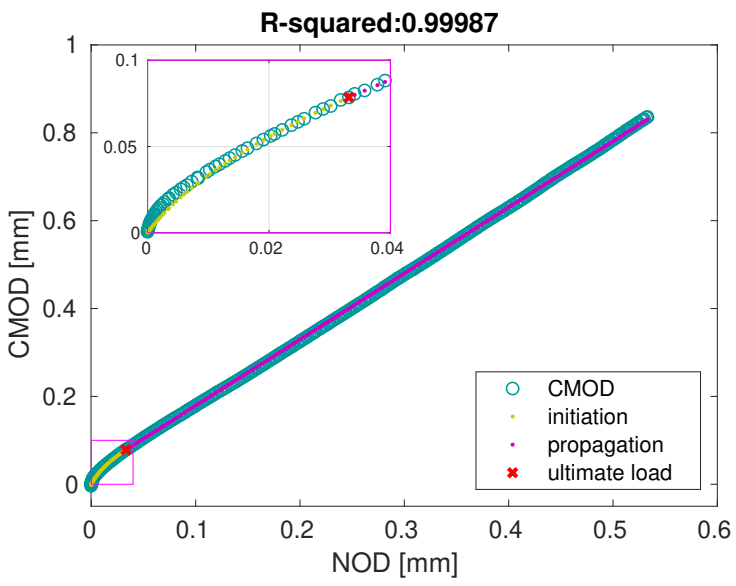

(b)

Figure 12: CMOD vs. NOD curves for the simulation of the monotonic test for the (a) front and (b) back face. The quadratic and affine fits are shown in yellow and purple, respectively. The insets (magenta boxes) concentrate on low levels of NOD and CMOD up to the ultimate load

For the cyclic test, the affine interpolation beyond the maximum force level also captures very well the CMOD vs. NOD relationship for the envelope (Figure 13). The slope $c$ of the latter (i.e., 1.52) is very close to those observed in Figure 12 even though the crack did not propagate as much as in the previous case. The early nonlinear response is also consistent with experimental observations (Figure 6). The coefficients of determination are close to unity and $\chi_{\Delta}=7$.

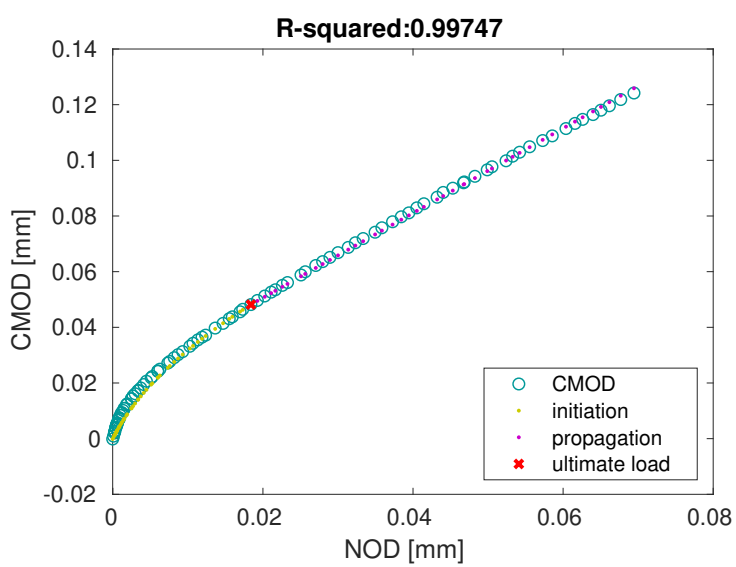

(a)

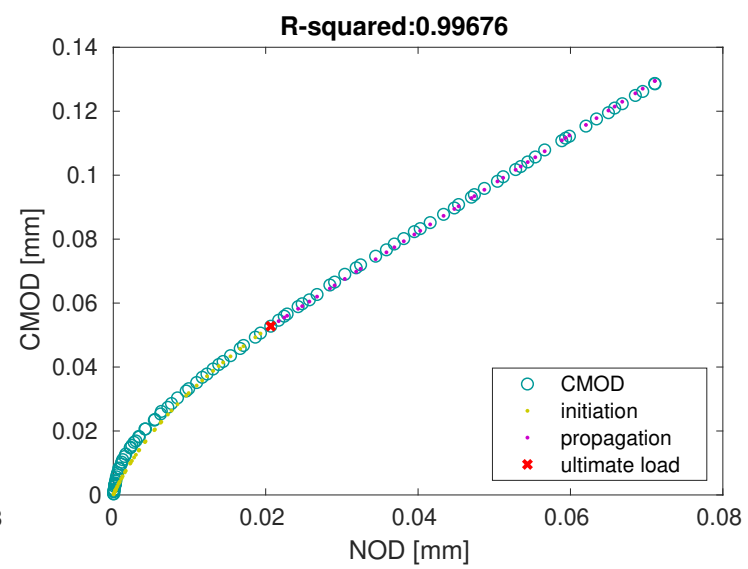

(b)

Figure 13: CMOD vs. NOD curves for envelope of the simulation of the cyclic test for the (a) front and (b) back face. The quadratic and affine fits are shown in yellow and purple, respectively

The results of the CZM are now shown for the full cyclic history. The general trends are in qualitative agreement with the experimental observations (Figure 7). In particular, no hysteresis is observed in the unloading/reloading cycles, which is to be expected from a damage model [58], be it written for a CZM. It is also worth noting that the CMOD/NOD relationship neglecting any non-linearity (Equation (4)) provides a lower bound, as also observed experimentally (Figure 7). 


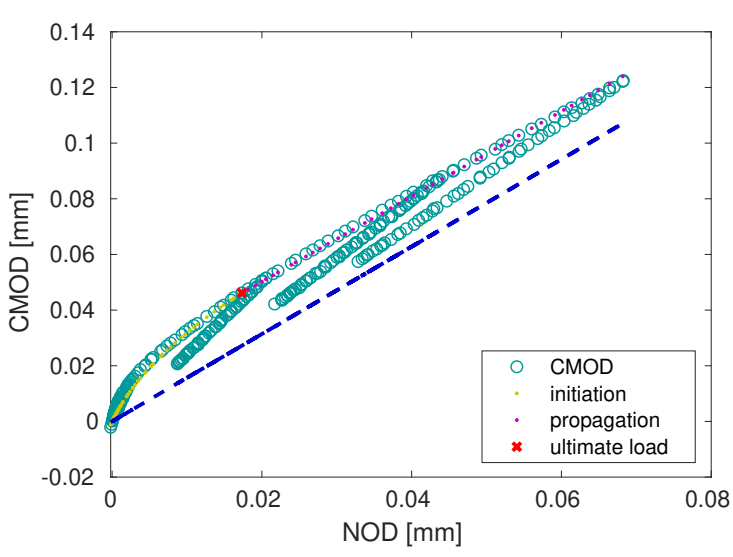

(a)

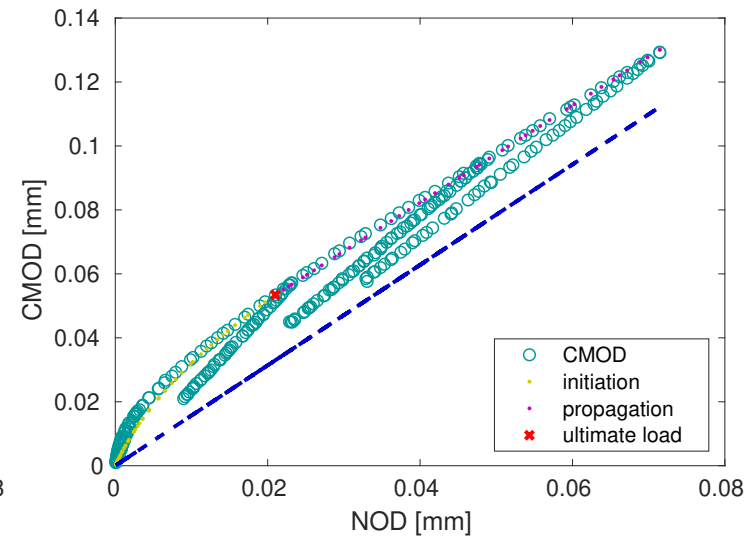

(b)

Figure 14: CMOD vs. NOD curves for the simulation of the cyclic test for the (a) front and (b) back faces. The affine fit is shown in yellow. The linear interpolation (blue) corresponds to Equation (4)

\section{Evaluation of Fracture Energies with NOD Data}

In previous analyses, two interpolations were introduced. First, a quadratic fit to describe the early phase of crack initiation and a subsequent affine interpolation starting from the peak load on to the end of the test. Second, a unique linear interpolation (with 1.57 slope) found in the brittle propagation case, which provides a lower bound to the CMOD level. Both interpolations and the experimental force vs. CMOD curves are shown in Figure 15. It is observed that the predictions based upon Equations (1)-(3) are in very good agreement, in every studied case, with the experimentally measured CMODs as expected from the levels of the coefficient of determination. The blue curves (obtained according to Equation (4)) were merely shifted to reach the same CMOD at peak load as experimentally measured. 


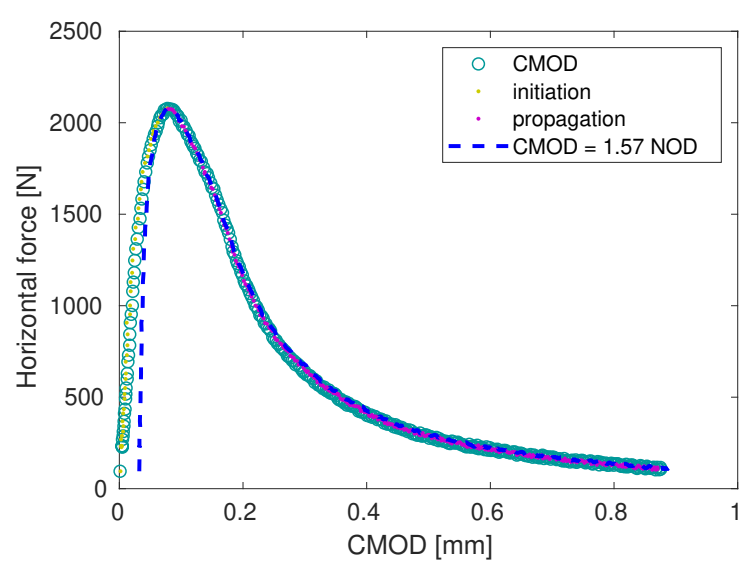

(a)

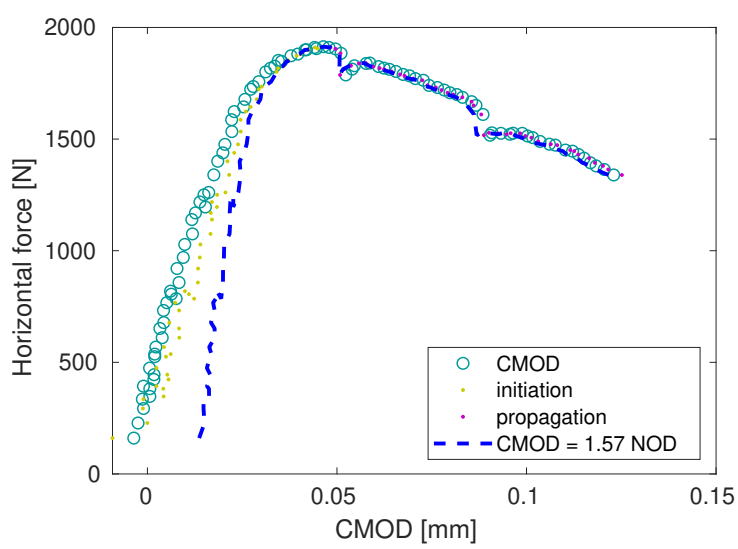

(c)

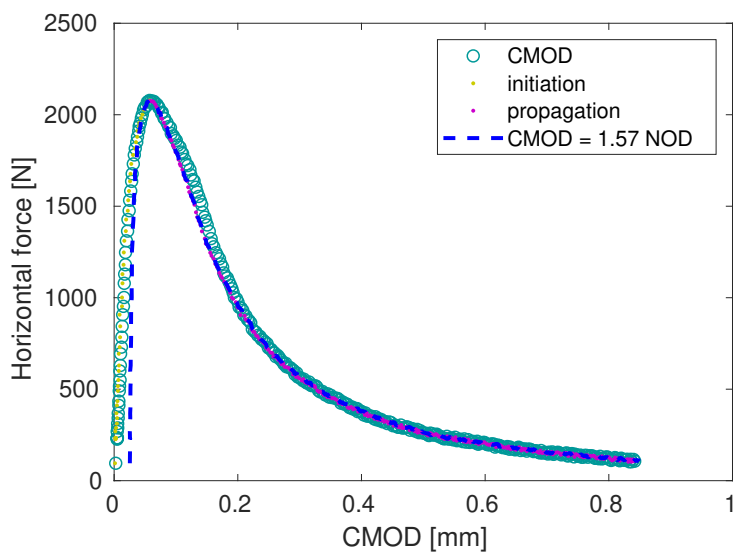

(b)

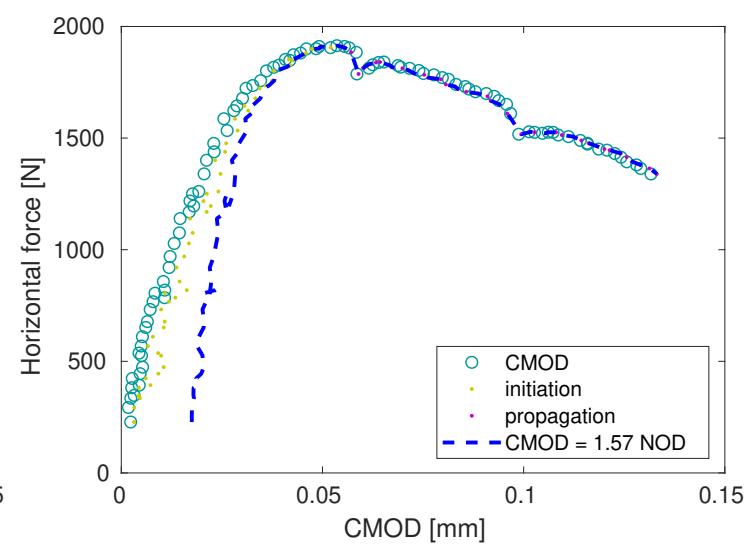

(d)

Figure 15: Horizontal forces vs. CMOD of the monotonic (a-b) and cyclic (envelope) (c-d) experiments for the front (a,c) and back (b,d). The experimental results are shown in green, while the interpolation proposed by Equation (1) in yellow (initiation) and purple (propagation) dots and by Equation (4) in a blue dashed line

From these plots, the part of the work of fracture spent for propagating the crack corresponds to the area under the curve constructed with the interpolation described by Equation (4). The total work of fracture being the integral of the $F / \Delta$ curve, the part of the energy used to initiate the crack corresponds to the difference between the previous quantities. For the monotonic test, these evaluations are straightforward since the applied force was very low at the end of the experiment (Figure 3). Conversely, for the cyclic test, the applied force before final unloading was still equal to $70 \%$ of the ultimate level (Figure 5). If the dissipated energy is sought at this stage, the unloading response would be needed to subtract the elastic energy. Such proposition was also made in Refs. [21, 22]. However, this path was not followed herein since the unloading response of the cyclic case shows that the calculation of the elastic energy is not straight forward since the unloading histories are complex as shown in Figure 5. If a lower bound to the fracture energy is to be assessed, the elastic part should not be subtracted since it will eventually be converted into dissipated energy. In the following analyses, the second route was followed.

The two contributions to the work of fracture until the load decreases down to $70 \%$ of the ultimate force (green and blue zones) are schematically drawn in Figure 16. Although the cyclic test did not lead to full propagation, the measured work may give a lower bound to the work of fracture (i.e., the hatched zone in Figure 16 is not accessible). Conversely, the initiation energy may be assessed in a more secure way as the peak load was reached. This description corroborates the crack initiation toughness calculated from peak load data as performed in Ref. [59]. Care should thus be taken when estimating the fracture energy since the area created by the propagating crack is not directly accessible in such cases except via DIC analyses [7]. 


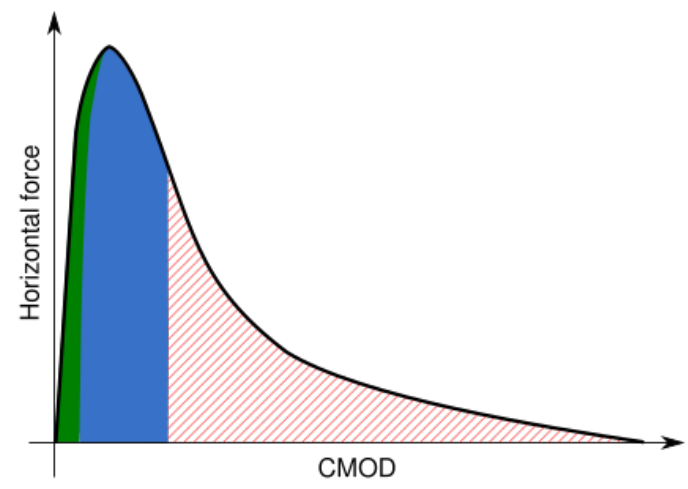

Figure 16: Schematic drawing showing the initiation energy (green), the evaluated propagation energy (blue), and the part of the propagation energy (red hatches) that is not accessible in the cyclic test

The curves reported in Figures 3(a) and 5(a) were utilized to estimate the work of fracture, and then the fracture energy by assuming that the fractured surface coincided with the central plane. For the cyclic test, the envelope of the vertical load vs. actuator displacement was integrated and the cracked surface was checked considering the average crack tip position (between both faces) at the end of the test via Integrated-DIC [7]. The work of fracture was then divided by twice the projected fracture area and the results for $\Gamma_{c}^{r a w}$ are shown in Table 2. For the two faces of any test, the work of fracture was also assessed from splitting force vs. CMOD data $\left(\Gamma_{c}^{C M O D}\right)$, provided CMOD measurements are available. This evaluation corresponds to the reference solution. It is observed that $\Gamma_{c}^{r a w}$ provides an upper bound as expected $[5,7]$. It is closer to $\Gamma_{c}^{C M O D}$ for the monotonic case when compared to the cyclic case. This difference is related to initial adjustment of the loading system and highlights how $\Gamma_{c}^{r a w}$ can be misleading (Figure 5). However, this initial difference is less important the more crack propagation occurred during the test. It is worth noting that the monotonic test reported herein presents a final loading of 5\% of the ultimate load, which is not always practical (several works report results up to $15 \%$ of the ultimate load [11, 12, 23-26, 37]).

Table 2

Fracture energies (in $\mathrm{J} / \mathrm{m}^{2}$ ) for the two WSTs evaluated from raw data as well as CMOD and NOD measurements

\begin{tabular}{|l||c|c|c|c|}
\hline Test & $\Gamma_{c}^{\text {raw }}$ & $\Gamma_{c}^{C M O D}$ & $\Gamma_{c}^{\text {NOD }}$ & $\Gamma_{p}^{\text {NOD }}$ \\
\hline \hline Monotonic (face 1) & 58.6 & $\mathbf{5 7 . 9}$ & 58.6 & 55.5 \\
Monotonic (face 2) & 58.6 & $\mathbf{5 3 . 9}$ & 53.3 & 50.6 \\
Cyclic (face 1) & 38.0 & $\mathbf{2 8 . 7}$ & 28.5 & 25.3 \\
Cyclic (face 2) & 38.0 & $\mathbf{3 0 . 1}$ & 29.6 & 27.5 \\
\hline
\end{tabular}

The proposed interpolation (Equations (1)-(2)) is also probed by expressing the CMOD from NOD measurements to evaluate the fracture energy $\Gamma_{c}^{N O D}$. However, if only NODs are measured, the CMOD can only be extrapolated using Equation (4), and then integrated with the splitting force to calculate the propagation energy $\Gamma_{p}^{N O D}$. These results are also reported in Table 2 . The proposed fit provides fracture energies very close to $\Gamma_{c}^{C M O D}$. The propagation energy $\Gamma_{p}^{N O D}$ comprises most of the total fracture energy, meaning that for this material, cracks are easily initiated but consume considerably more energy during propagation as expected from the low firing temperature and underlying microstructure [16].

In the present setting, $\Gamma_{c}^{C M O D}$ provides the fracture energy and $\Gamma_{p}^{N O D}$ the propagation energy, their difference (i.e., $\Gamma_{i}^{C M O D}$ ) corresponds to the initiation energy. The averages of these values, between both faces for each test, are reported in Table 3. Although the propagation energy was very different since the cyclic test was stopped prior to full propagation, the initiation energy remained very close. Even if only one of the tests had lateral grooves to guide the crack, the results are consistent. 


\section{Table 3}

Fracture, propagation and initiation energies (in $\mathrm{J} / \mathrm{m}^{2}$ ) evaluated for both tests with experimental data

\begin{tabular}{|l|c|c|c|}
\hline Test & $\Gamma_{c}^{C M O D}$ & $\Gamma_{p}^{N O D}$ & $\Gamma_{i}^{C M O D}$ \\
\hline \hline Monotonic & 55.9 & 53.0 & 2.9 \\
\hline Cyclic & 29.4 & 26.4 & 3.0 \\
\hline
\end{tabular}

The same analyses are performed utilizing the CZM predictions in Figure 17. Very similar trends are observed when compared to the experimental results from Figure 15. A slight difference can be seen in the initial slope of the dashed blue curves due to the high stiffness in the cohesive elements at the beginning of the test.

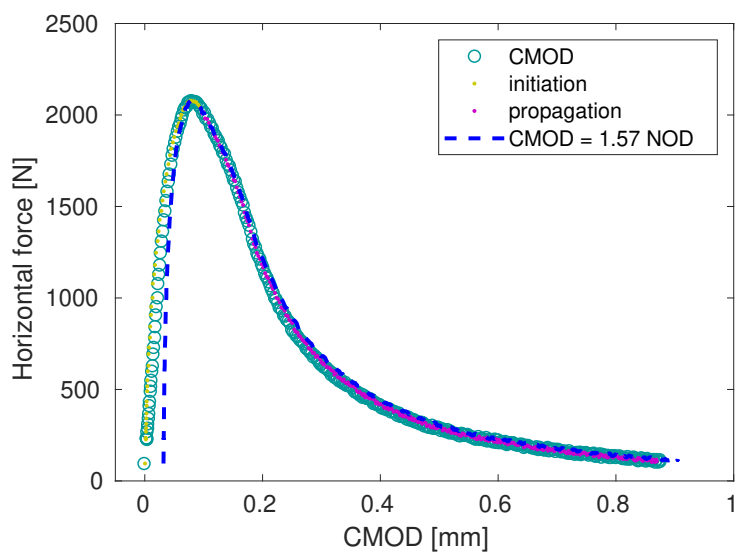

(a)

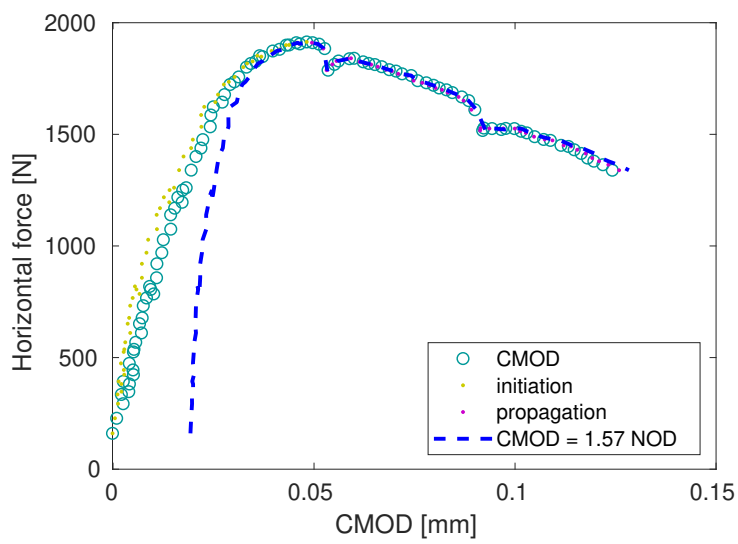

(c)

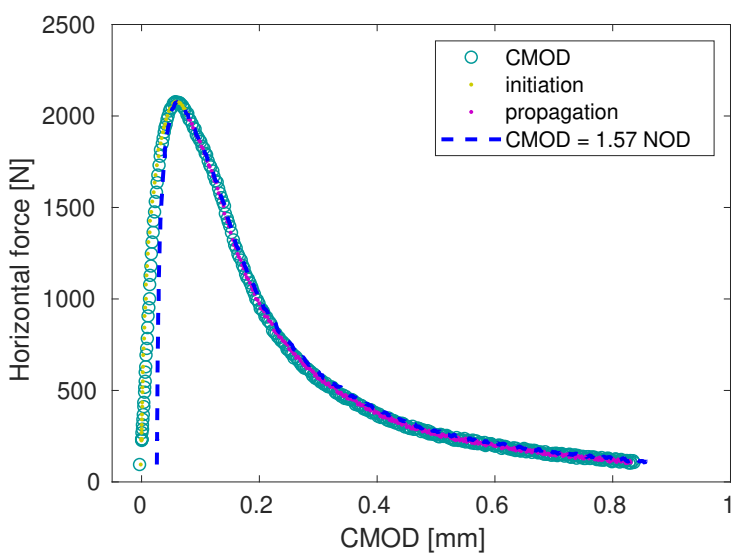

(b)

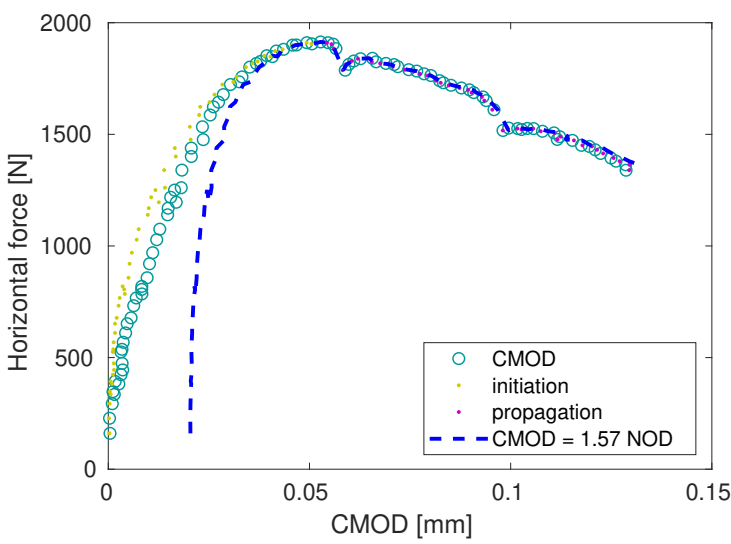

(d)

Figure 17: Horizontal forces vs. CMOD predicted by the calibrated CZM applied to the monotonic (a-b) and cyclic (envelope) (c-d) experiments for the front $(a, c)$ and back $(b, d)$ faces. The experimental results are shown in green, while the interpolation proposed by Equation (1) in yellow (initiation) and purple (propagation) dots and by Equation (4) in a blue dashed line

The fracture energy $\Gamma_{c}^{C Z M}$ was assessed with the predicted force vs. CMOD history (Figure 17) and is reported in Table 4. A very good agreement is observed in comparison to experimental levels (Table 2). Similarly, the proposed NOD/CMOD interpolation leads to consistent levels for $\Gamma_{c}^{C Z M-N O D}$ in comparison to $\Gamma_{c}^{C Z M}$. The same agreement is observed between the propagation energy assessed with experimental data $\left(\Gamma_{p}^{N O D}\right)$ and the $\mathrm{CZM}\left(\Gamma_{p}^{C Z M}\right)$. 


\section{Table 4}

Fracture energies (in $\mathrm{J} / \mathrm{m}^{2}$ ) for the two WSTs evaluated from raw data as well as CMOD and NOD measurements or predictions with the calibrated CZM

\begin{tabular}{|l||c|c|c|c|}
\hline Test & $\Gamma_{c}^{\text {raw }}$ & $\Gamma_{c}^{C Z M}$ & $\Gamma_{c}^{C Z M-N O D}$ & $\Gamma_{p}^{C Z M}$ \\
\hline \hline Monotonic (face 1) & 58.6 & $\mathbf{5 7 . 5}$ & 58.5 & 56.5 \\
\hline Monotonic (face 2) & 58.6 & $\mathbf{5 4 . 1}$ & 55.0 & 52.5 \\
\hline Cyclic (face 1) & 38.0 & $\mathbf{2 8 . 3}$ & 29.3 & 26.3 \\
\hline Cyclic (face 2) & 38.0 & $\mathbf{2 9 . 8}$ & 30.7 & 27.3 \\
\hline
\end{tabular}

\section{Application of the Proposed Methodology: Monotonic Test on A-MZ Castable}

The following analysis deals with a WST that belongs to the category of experiments for which the NOD history could be measured but not the CMOD (Figure 1(b)). In the present case, it is an alumina matrix with low cement content, and with aggregates made of fused mullite-zirconia. For the oxide composition, it contains $\mathrm{Al}_{2} \mathrm{O}_{3}, \mathrm{ZrO}_{2}$, $\mathrm{SiO}_{2}, \mathrm{CaO}$ and $\mathrm{Fe}_{2} \mathrm{O}_{3}$, in decreasing content order (i.e., $86.0 \mathrm{wt} \%$ of $\mathrm{Al}_{2} \mathrm{O}_{3}$, but only $0.1 \mathrm{wt} \%$ of $\mathrm{Fe}_{2} \mathrm{O}_{3}$ ). The castable was fired at $1450^{\circ} \mathrm{C}$ and subsequently tested at room temperature [41]. Grooves were implemented on the front and back faces (Figure 1(b)) to prescribe the crack path to be straight with a slightly bigger thickness (i.e., $75 \mathrm{~mm}$ ) in comparison to Figure 2(b) and a total thickness reduction of $20 \mathrm{~mm}$ instead of $7 \mathrm{~mm}$. The NOD history is reported in Figure 18(a) as a function of the (horizontal) splitting force. The overall trends are similar to those observed on the applied load vs. actuator displacement (Figure 18(b)).

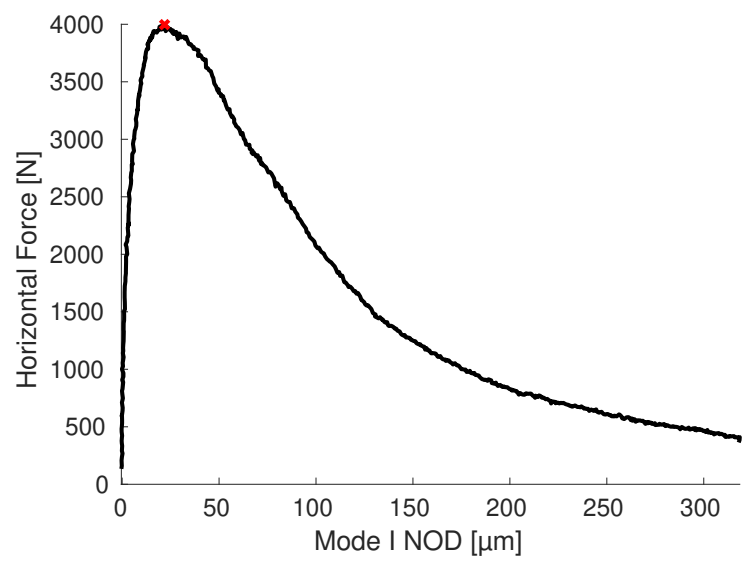

(a)

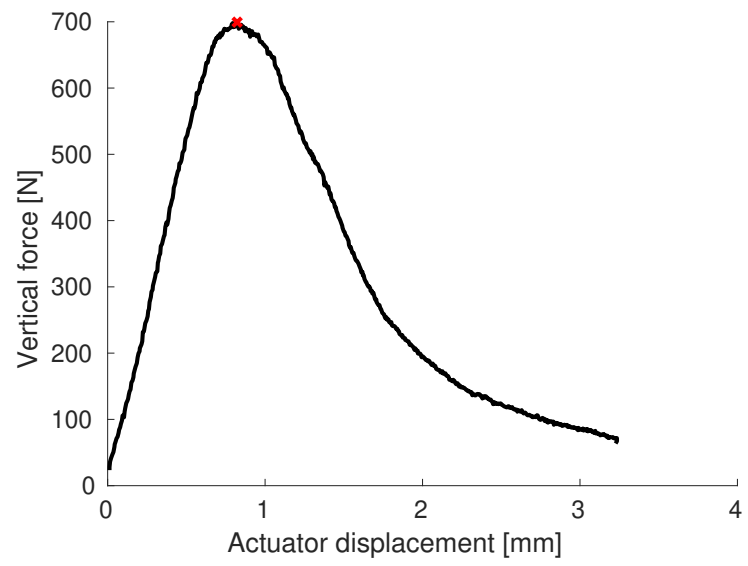

(b)

Figure 18: Loading curves with results (a) converted to horizontal forces coupled with DIC measurements, and (b) directly obtained from testing machine data. The red crosses depict the ultimate force level

For this last experiment, one hundred pictures of the reference configuration were acquired prior to the WST itself. Consequently, the uncertainties were evaluated with this experimental set of pictures. The standard NOD and CMOD uncertainty $\sigma_{u}$ was equal to $1.5 \mathrm{cpx}($ or $0.29 \mu \mathrm{m}$ ) in the horizontal direction. This level is about three times that observed in the previous case. The experimental conditions were very different, and in particular, the speckle pattern (Figure 1(b)) was not as contrasted as in the other cases (Figures 3(b-c) and 5(b-c)). With such low uncertainties, the NODs reported in Figure 18(a) are also deemed trustworthy.

The curves reported in Figure 18 were analyzed as previously to estimate the propagation energy by assuming that the fractured surface coincided with the central plane [41]. The results are shown in Table 5. Since the CMOD could not be measured, only the propagation energy could be evaluated. Both estimates $\Gamma_{c}^{r a w}$, assessed from testing machine data (Figure 18(b)) and $\Gamma_{p}^{N O D}$ from the NOD measurements (Figure 18(a)), provide upper and lower bounds to the fracture energy. The upper bound is associated with $\Gamma_{c}^{r a w}$ as shown in the previous analyses. Conversely, $\Gamma_{p}^{N O D}$ provides a lower bound since it only accounts for the propagation energy. 


\section{Table 5}

Upper and lower bounds to the fracture energy (in $\mathrm{J} / \mathrm{m}^{2}$ ) for the test on Alumina-Mullite-Zirconia castable from raw data (Figure 18(b)) as well as DIC measurements (Figure 18(a) and Equation (4))

\begin{tabular}{|l|c|c|}
\hline Test & $\Gamma_{c}^{\text {raw }}$ & $\Gamma_{p}^{\text {NOD }}$ \\
\hline \hline MZ1-S1450G & 140 & 119 \\
\hline
\end{tabular}

One further evidence that the present estimations are trustworthy is that, for each test presented herein, no level was greater than the upper-bound given by $\Gamma_{c}^{r a w}$. Compared to $\Gamma_{c}^{C M O D}$ or $\Gamma_{p}^{N O D}, \Gamma_{c}^{r a w}$ is on average $22 \%$ higher, in line with earlier statements and findings [5, 7].

It is worth noting that the two refractories studied herein have very different compositions and microstructures. Moreover, the Alumina-Mullite-Zirconia castable was fired at $1450^{\circ} \mathrm{C}$ while the DD 40 grade at $540^{\circ} \mathrm{C}$. This processing parameters lead to very different properties that may be beneficial in distinct applications. In particular, their propagation energies were twice as high for the Alumina-Mullite-Zirconia castable compared to the DD40 grade when assessed with the same experiment (WST) and sample geometry. Although the alumina-based material is expected to exhibit a smaller fracture process zone than the DD40 grade, the findings reported herein indicate that such difference in brittleness (similar to that reported in Ref. [11] between pure $\mathrm{MgO}$ and $\mathrm{MgO}$ with spinel) may only affect the nonlinear region of the NOD vs. CMOD response with the ultimate load achieved for smaller displacements. Thus, the multiplicative factor for the post-peak regime is expected to be valid for materials with very different brittleness.

\section{Conclusion}

Images from both sides of two Wedge Splitting Tests (WSTs), one monotonic performed on a ungrooved sample (with complete crack propagation) and one cyclic on a grooved sample (post-peak stopped at $70 \%$ of the maximum load), were analyzed with Digital Image Correlation (DIC) to study the relationship between Crack Mouth Opening Displacements (CMODs) and Notch Opening Displacements (NODs). A nonlinear relationship was observed at the beginning of the test (i.e., during crack initiation) that was shown to be well described by a quadratic function. In the post-peak part (i.e., propagation regime), the relationship remained essentially affine. The key element to transition from both regimes is the CMOD/NOD ratio at the ultimate load.

Such displacement data were also extracted from finite element simulations using cohesive elements whose parameters were calibrated in both analyzed experiments via FEMU-F. All the previous trends were very well reproduced by the cohesive zone model. Another simulation was performed to study brittle propagation by sequentially splitting nodes along the crack propagation path. A linear relationship between CMOD and NOD data was obtained, thereby corroborating the experimental results for the post-peak crack propagation regime.

Last, the motivation of this study was to analyze one experiment where the region for CMOD measurement was not observable (Figure 1(b)). With the measured NOD history it was possible to evaluate the crack propagation fracture energy, which together with the raw measurements from the testing machine yielded lower and upper bounds to the fracture energy, respectively. For future studies, the calibration of cohesive zone models from NOD data would be a direct continuation.

\section{Acknowledgments}

This study was financed in part by the Coordenação de Aperfeiçoamento de Pessoal de Nível Superior - Brasil (CAPES) - Finance Code 001 CAPES (Brazil) and \#2018/15266-0, \#2018/23081-0, and \#2010/20920-9, São Paulo Research Foundation (FAPESP). The authors would like to thank Prof. J.A. Rodrigues for stimulating discussions about various aspects of WSTs and IBAR (Indústrias Brasileiras de Artigos Refratários, Poá, Brazil) for kindly providing the materials.

\section{Credit authorship statement}

R. Vargas: Conceptualization, Methodology, Investigation, Software, Original draft preparation, Writing - Review \& Editing

R.B. Canto: Supervision, Conceptualization, Writing - Review \& Editing, Resources, Funding acquisition, Project administration 
F. Hild: Supervision, Conceptualization, Methodology, Software, Formal analysis, Writing - Review \& Editing, Resources, Funding acquisition, Project administration

\section{Declaration of Competing Interest}

The authors declare that they have no known competing financial interests or personal relationships that could have appeared to influence the work reported in this paper.

\section{References}

[1] H. N. Linsbauer, E. K. Tschegg, Fracture energy determination of concrete with cube shaped specimens, Zement und Beton 31 (1986) $38-40$.

[2] E. Tschegg, Prüfeinrichtung zur Ermittlung von bruchmechanishen Kennwerten sowie hiefür geeignete, Prüfkörper, Austrian Pat. AT 390328B, registered (1986).

[3] H. Harmuth, Stability of crack propagation associated with fracture energy determined by wedge splitting specimen, Theoretical and Applied Fracture Mechanics 23 (1995) 103-108.

[4] H. Harmuth, E. K. Tschegg, A fracture mechanics approach for the development of refractory materials with reduced brittleness, Fatigue \& Fracture of Engineering Materials \& Structures 20 (11) (1997) 1585-1603.

[5] E. Brühwiler, F. H. Wittmann, The wedge splitting test, a new method of performing stable fracture mechanics tests, Engineering Fracture Mechanics 35 (1-3) (1990) 117-125.

[6] S. Ribeiro, C. C. D. Exposito, J. A. Rodrigues, Projeto, adaptação, instalação e testes preliminares para um sistema de medida de energia de fratura de materiais cerâmicos pelo método da cunha, Cerâmica 54 (2008) 418-426.

[7] R. Vargas, J. Neggers, R. B. Canto, J. A. Rodrigues, F. Hild, Comparison of two full-field identification methods for the wedge splitting test on a refractory, Journal of the European Ceramic Society 38 (16) (2018) 5569 - 5579.

[8] J. Poirier, E. Blond, E. Bilbao, R. Michel, A. Coulon, J. Gillibert, M. Boussuge, Y. Zhang, D. Ryckelynk, G. Dusserre, T. Cutard, P. Leplay, New advances in the laboratory characterization of refractories: testing and modelling, Metallurgical Research \& Technology 114 (6) (2017) 610 .

[9] M. Sutton, Computer vision-based, noncontacting deformation measurements in mechanics: A generational transformation, Appl. Mech. Rev. 65 (AMR-13-1009) (2013) 050802

[10] R. Vargas, J. Neggers, R. B. Canto, J. A. Rodrigues, F. Hild, Analysis of a castable refractory using the wedge splitting test and cohesive zone model, Journal of the European Ceramic Society 39 (13) (2019) 3903-3914.

[11] I. Khlifi, O. Pop, J.-C. Dupré, P. Doumalin, M. Huger, Investigation of microstructure-property relantionships of magnesia-hercynite refractory composites by a refined digital image correlation technique, Journal of the European Ceramic Society 39 (13) (2019) $3893-3902$.

[12] D. A., R. Estevez, M. Thibault, P. Leplay, Fracture and cohesive parameter identification of refractories by digital image correlation up to $1200{ }^{\circ} \mathrm{c}$, Experimental Mechanics (2020).

[13] Y.-K. Hou, S.-J. Duan, R.-M. An, Solving the cohesive zone model analytic function for concrete based on wedge-splitting test on a compact tension specimen, Theoretical and Applied Fracture Mechanics 102 (2019) 162-170.

[14] P. Bokam, A. Germaneau, P. Rigoard, T. Vendeuvre, V. Valle, Cancellous bone and PMMA cement interfacial fracture properties evaluation using heaviside digital image correlation/wedge splitting test method, Computer Methods in Biomechanics and Biomedical Engineering 23 (sup1) (2020) S38-S39.

[15] P. Bokam, A. Germaneau, P. Rigoard, T. Vendeuvre, V. Valle, Evaluation of fracture properties of cancellous bone tissues using digital image correlation/wedge splitting test method, Journal of the mechanical behavior of biomedical materials 102 (2020) 103469.

[16] R. Vargas, J. Neggers, R. B. Canto, J. A. Rodrigues, F. Hild, Analysis of wedge splitting test on refractory castable via integrated DIC, Journal of the European Ceramic Society 36 (16) (2016) 4309-4317.

[17] A. Jamaaoui, O. Pop, R. Ktari, A. Millien, C. Petit, Analyzing of wedge splitting test on asphalt pavement using optical measurements, Journal of Testing and Evaluation 45 (6) (2017) 1959-1970.

[18] A. Jamaaoui, O. Pop, F. Dubois, G. Costa, Wedge Splitting Test on Douglas genotypes using an integrated mixed-mode approach, Theoretical and applied fracture mechanics 91 (2017) 44-51.

[19] C. Jailin, A. Bouterf, R. Vargas, F. Hild, S. Roux, Sub-minute In Situ Fracture Test in a Laboratory CT Scanner, Integrating Materials and Manufacturing Innovation 8 (3) (2019) 413-422.

[20] J. Lemery, M. B. Ftima, M. Leclerc, C. Wang, The disturbed fracture process zone theory for the assessment of the asymptotic fracture energy of concrete, Engineering Fracture Mechanics 231 (2020) 107022.

[21] Y. Belrhiti, O. Pop, A. Germaneau, P. Doumalin, J. C. Dupré, H. Harmuth, M. Huger, T. Chotard, Investigation of the impact of micro-cracks on fracture behavior of magnesia products using wedge splitting test and digital image correlation, Journal of the European Ceramic Society 35 (2) (2015) 823-829.

[22] Y. Belrhiti, O. Pop, A. Germaneau, P. Doumalin, J. C. Dupré, M. Huger, T. Chotard, Refinement of digital image correlation technique to investigate the fracture behaviour of refractory materials, in: IOP Conference Series: Materials Science and Engineering, Vol. 119, 2016, p. 012010

[23] Y. Dai, D. Gruber, H. Harmuth, Observation and quantification of the fracture process zone for two magnesia refractories with different brittleness, Journal of the European Ceramic Society 37 (6) (2017) 2521-2529.

[24] Y. Dai, D. Gruber, H. Harmuth, Determination of the fracture behaviour of MgO-refractories using multi-cycle wedge splitting test and digital image correlation, Journal of the European Ceramic Society 37 (15) (2017) 5035-5043. 


\section{Fracture Energy Evaluation of Refractories in Wedge Splitting Tests from Notch Opening Displacements}

[25] Y. Dai, Y. Li, X. Xu, Q. Zhu, Y. Yin, S. Ge, A. Huang, L. Pan, Characterization of tensile failure behaviour of magnesia refractory materials by a modified dog-bone shape direct tensile method and splitting tests, Ceramics International 46 (5) (2020) 6517-6525.

[26] Y. Dai, Y. Li, S. Jin, H. Harmuth, Y. Wen, X. Xu, Mechanical and fracture investigation of magnesia refractories with acoustic emission-based method, Journal of the European Ceramic Society 40 (1) (2020) 181-191.

[27] Y. Dai, Y. Li, S. Jin, H. Harmuth, X. Xu, Fracture behavior of magnesia refractory materials under combined cyclic thermal shock and mechanical loading conditions, Journal of the American Ceramic Society 103 (3) (2020) 1956-1969.

[28] Y. Dai, H. Harmuth, S. Jin, D. Gruber, Y. Li, R-curves determination of ordinary refractory ceramics assisted by digital image correlation method, Journal of the European Ceramic Society (2020).

[29] J. C. Dupré, P. Doumalin, Y. Belrhiti, I. Khlifi, O. Pop, M. Huger, Detection of cracks in refractory materials by an enhanced digital image correlation technique, Journal of Materials Science 53 (2) (2018) 977-993.

[30] S.-H. Hong, J.-W. Lee, J.-H. Kim, S.-Y. Lee, J.-B. Park, G.-D. Jung, Evaluation of Fracture Behavior on Particle Reinforced Composite Using Digital Image Correlation, Journal of the Korean Society for Aeronautical \& Space Sciences 46 (7) (2018) 535-541.

[31] S. D. Kim, D. H. Yoon, S. Y. Lee, J. H. Kim, Crack resistance behavior of particulate reinforced composites at various test speeds and temperatures, Materialwissenschaft und Werkstofftechnik 51 (5) (2020) 603-612.

[32] D. Y. Liu, K. P. Su, A. M. Deng, Study on the Constitutive Behavior and Damage Evolution in the FPZ of WST Specimens Using the Vic-2D and Strain Gauges, in: Advanced Materials Research, Vol. 744, Trans Tech Publ, 2013, pp. 161-164.

[33] S. H. Na, J. H. Kim, H. S. Choi, J. B. Park, S. H. Kim, G. D. Jung, Wedge splitting test and fracture energy on particulate reinforced composites, Transactions of the Korean Society of Mechanical Engineers A 40 (3) (2016) 253-258.

[34] S. H. Na, J. W. Lee, J. H. Kim, Crack resistance behavior using digital image correlation and crack tip opening angle on particulate reinforced composite, Transactions of the Korean Society of Mechanical Engineers A 40 (12) (2016) 1021-1026.

[35] S. H. Na, J. W. Lee, J. H. Kim, J. B. Park, G. D. Jung, An experimental study of the fracture behavior of particulate reinforced composites using digital image correlation, Materialwissenschaft und Werkstofftechnik 48 (5) (2017) 349-357.

[36] K. Ostapska, K. A. Malo, Wedge splitting test of wood for fracture parameters estimation of norway spruce, Engineering Fracture Mechanics (2020) 107024.

[37] Z. Pan, S. Huang, Y. Su, M. Qiao, Q. Zhang, Strain field measurements over $3000^{\circ} \mathrm{C}$ using 3D-digital image correlation, Optics and Lasers in Engineering 127 (2020) 105942.

[38] Ł. Skarżyński, J. Suchorzewski, Mechanical and fracture properties of concrete reinforced with recycled and industrial steel fibers using Digital Image Correlation technique and X-ray micro computed tomography, Construction and Building Materials 183 (2018) $283-299$.

[39] J. Suchorzewski, M. Prieto, U. Mueller, An experimental study of self-sensing concrete enhanced with multi-wall carbon nanotubes in wedge splitting test and DIC, Construction and Building Materials 262 (2020) 120871.

[40] E. Brochen, C. Dannert, P. Quirmbach, Thermo-mechanical characterisation of magnesia-carbon refractories by means of wedge splitting test under controlled atmosphere at high-temperature, in: Proceedings of the Unified International Technical Conference on Refractories (UNITECR 2013), Wiley Online Library, 2014, pp. 53-58.

[41] R. Vargas, X. Pinelli, B. Smaniotto, F. Hild, R. Canto, Effect of sintering temperature on fracture energy of Alumina-Mullite-Zirconia castable at $600^{\circ} \mathrm{C}$, Journal of the European Ceramics Society (2021) DOI: 10.1016/j.jeurceramsoc.2021.01.023.

[42] M. D. Cabrelon, A. H. A. Pereira, J. Medeiros, R. D. Toledo-Filho, J. A. Rodrigues, Efeito do tempo de exposição a uma atmosfera coqueificante na microestrutura e nas propriedades de um concreto refratário usado na indústria petroquímica, Cerâmica 58 (2012) $195-204$.

[43] D. Y. Miyaji, C. Z. Otofuji, M. D. Cabrelon, J. Medeiros, J. A. Rodrigues, The coke effect on the fracture energy of a refractory castable for the petrochemical industry, in: Proceedings of the Unified International Technical Conference on Refractories (UNITECR 2013), Wiley Online Library, 2014, pp. 1111-1116.

[44] A. H. A. Pereira, D. Y. Miyaji, M. D. Cabrelon, J. Medeiros, J. A. Rodrigues, A study about the contribution of the $\alpha$ - $\beta$ phase transition of quartz to thermal cycle damage of a refractory used in fluidized catalytic cracking units, Cerâmica 60 (2014) 449-456.

[45] D. B. D. Stafuzza, J. A. Rodrigues, D. Miyaji, R. B. Canto, Application of the digital image correlation technique to the fracture energy method for refractory concretes, in: Congresso Brasileiro de Engenharia e Ciência dos Materiais - $20^{\circ}$ CBECiMat, Joinville, 2012, pp. 2300-2307, (In Portuguese).

[46] V. F. Sciuti, R. Vargas, R. Canto, F. Hild, Pyramidal Adaptive Meshing for Digital Image Correlation Dealing With Cracks, Submitted for publication (2021).

[47] R. J. Bucci, Selecting aluminum alloys to resist failure by fracture mechanisms, Engineering Fracture Mechanics 12 (3) (1979) $407-441$.

[48] S. Xu, X. Zhang, Determination of fracture parameters for crack propagation in concrete using an energy approach, Engineering Fracture Mechanics 75 (15) (2008) 4292-4308.

[49] S. E. Stanzl-Tschegg, P. Navi, Fracture behaviour of wood and its composites. A review COST Action E35 2004-2008: wood machiningmicromechanics and fracture, Holzforschung 63 (2) (2009) 139-149.

[50] T. Ikeda, T. Umetani, N. Kai, K. Ogi, N.-A. Noda, Y. Sano, Influence of silicon content, strain rate and temperature on toughness and strength of solid solution strengthened ferritic ductile cast iron, Materials Transactions (2016) F-M2016832.

[51] S. S. M. Tavares, H. F. Abreu, T. R. Strohaecker, M. B. Silva, M. C. S. de Macêdo, Influence of heat treatments on the impact toughness of a ti-stabilized 12\% cr supermartensitic stainless steel, Materials research 20 (2) (2017) 469-473.

[52] M. Erdmann, U. Niebergall, V. Wachtendorf, M. Böhning, Evaluation of UV-induced embrittlement of PE-HD by Charpy impact test, Journal of Applied Polymer Science (2020) 49069.

[53] Y. Ye, S. Tang, Z. Xi, Brittleness evaluation in shale gas reservoirs and its influence on fracability, Energies 13 (2) (2020) 388.

[54] I. Löfgren, J. Olesen, M. Flansbjer, The WST-method for fracture testing of fibre-reinforced concrete, Nordic Concrete Research 34 (2) (2005) 15-33.

[55] K. Park, G. H. Paulino, J. R. Roesler, A unified potential-based cohesive model of mixed-mode fracture, Journal of the Mechanics and Physics of Solids 57 (6) (2009) 891-908. 
[56] K. Park, G. H. Paulino, Computational implementation of the PPR potential-based cohesive model in ABAQUS: educational perspective, Engineering Fracture Mechanics 93 (2012) 239-262.

[57] R. Vargas, A. Tsitova, F. Bernachy-Barbe, B. Bary, R. Canto, F. Hild, On the identification and validation of fracture mechanics models for curved crack in mortar, Strain 56 (6) (2020) e12364.

[58] J. Lemaitre, A Course on Damage Mechanics, 2nd Edition, Springer-Verlag, Berlin (Germany), 1992. doi: 10.1007/978-3-642-18255-6.

[59] L. Qing, Q. Li, A theoretical method for determining initiation toughness based on experimental peak load, Engineering Fracture Mechanics 99 (2013) 295-305. 